\title{
Changing systems for supporting farmers' decisions: problems, paradigms, and prospects
}

\author{
R.L. McCown* \\ APSRU, CSIRO Sustainable Ecosystems, 203 Tor Street, Toowoomba, QLD 4350, Australia
}

Accepted 18 March 2002

\begin{abstract}
All correct reasoning is a grand system of tautologies, but only God can make direct use of that fact. The rest of us must painstakingly and fallibly tease out the consequences of our assumptions. (Herbert Simon in 'The Sciences of the Artificial', p.15)
\end{abstract}

Decision support systems (DSS), like other information systems (IS) before them, were designed to serve functions deemed by 'management scientists' to be potentially useful to managers. But the unwelcome fact is that the use of agricultural DSSs by managers of farms has been low. This paper probes possible reasons for this through interpretation of agricultural DSS case histories and several strands of relevant social theory. From nine cases of DSS development effort and 14 products interpreted comparatively, a number of generalisations are made that serve as reference points in the following search for explanation in theory.

First, the nature of management practice of family farms is explored and differences between the internal structure governing personal action and the scientific approach to practice are contrasted. Next, the interaction between the nature of the particular action/practice and the nature of the DSS is explored. A DSS designed to provide integrated, optimal recommendations for management typifies the DSS as a proxy for a manager's decision process. Examples of elaborate expert systems that simply were not used dramatically illustrate the resistance of family farmers to have their decision processes by-passed. On the other hand, the DSS designed to serve as a tool in a modified decision process is shown to have experienced higher use, by deriving and exploiting 'deep,' abstract information about the system, by introducing a powerful 'logic,' or a combination of both.

* Tel.: + 61-7-4688-1390; fax: +61-7-4688-1193.

E-mail address: bob.mccown@csiro.au (R.L. McCown). 
A number of the referenced case stories demonstrate the resurgence of the decision support mode whereby the simulator is in the hands of an expert intermediary as an alternative to easy-to-use software in the hands of a farmer. This is the mode of operational research/ management science, which preceded the DSS.

In comparison with hierarchical organizations, available options for overcoming the persistent 'problem of implementation' of the DSS in family farms are inherently weak. This focuses attention on the importance of the relationship between the DSS developer and the potential user. Drawing on a classic typology of possible configurations of 'understanding' between the scientist and the manager, four approaches to intervention are discussed. Three entail a degree of engagement that qualifies them as 'participative.' But one of these constitutes a departure from the DSS and broader IS traditions that places it in another paradigm. In this 'mutual understanding' relationship, intervention intent shifts from educating and persuading to recognition of and respect for other ways of viewing the world. This opens up the opportunities for co-creating information systems that utilise the comparative advantages of both practical and scientific knowledge. Intervention emphasis shifts from prescribing action to facilitating learning in actions.

Although the DSS has fallen far short of expectations in its influence on farm management, the experience has been instructive in multiple ways to both farmers and professionals in agriculture. In many cases, farmers learned from the DSS and could then jettison it without loss. From disappointments scientists have sometimes learned what was needed to achieve a better outcome. From collated DSS experiences, important lessons for the future can be drawn.

The paper concludes by conjecturing that the future of the DSS and related ISs, while more limited than once imagined, holds promise in four directions: a 'small' tool for aiding farmers' tactical decisions; a versatile simulator as a consultant's tool; a versatile simulator as the core of a facilitated 'learning laboratory,' and a formal framework that supports regulatory objectives in constraining and documenting farming practice. (C) 2002 Elsevier Science Ltd. All rights reserved.

Keywords: Decision support system; Evaluation; Decision tool; Decision proxy; Intervention paradigms; Simulation model; Experiential learning; Action research

\section{Introduction}

In the opening paper of this Special Issue (McCown et al., 2002), the claim is made that the field of agricultural decision support systems is in a state of crisis similar to that which occurred in Operations Research/Management Science in the 1970s. Within the decade of the 1990s, decision support system (DSS) research has fallen from its zenith as a research priority to being talked about, increasingly, in the past tense. Yet, the fundamental rationale for the DSS venture still seems remarkably appealing: information technology making agricultural systems science more accessible and useful for guiding management of production systems. It still seems tenable that a scientifically sound DSS should be useful to a farmer, and both models and computer software have improved immensely in their capabilities and ease of use. There has been no diminution of farmers' need for good planning and decisionmaking. And most importantly, the case history papers provide evidence that learning and re-invention has been taking place, and that some new efforts show significant signs of success. 
Future prospects of this field of RD\&E, the subject of a later section of this paper, depend on such 'bright spots.' But the future of the DSS may depend no less on what has been learned from decades of problems and failure to achieve widespread use of this technology in farm management practice. The fact that the generally disappointing outcome of the broad agricultural DSS effort has been such a surprise seems a compelling and sufficient reason for serious attention being given to the nature of the so-called 'problem of implementation' and to theoretical avenues for remedies. Hundreds of papers and books have been written on the problem, almost entirely outside agriculture, and yet the problem persists there as well. But the search for a solution has stimulated enormous progress in 'systems' thinking and methodology with regard to the way the social dimension of decision support is treated. These changes began to influence the broader interface between research and farming practice in the 1980s (e.g. Roling, 1988), and have more recently begun to challenge the thinking about the way agricultural models and DSSs are built and used (Cox, 1996; McCown, 2001). This is no less than a new paradigm for information systems development (ISD ${ }^{1}$ ) aimed at intervention in human actions (Hirschheim et al., 1995). In this paradigm the problem of 'implementation' gives way to the problem of how to achieve 'mutual understanding' between interventionists and practitioners and to 'intervention' that is less about recommendation that by-passes a farmer's decision process and more about facilitation of decision process adaptation.

I begin with comparison of 14 DS products in nine RD\&E case histories, six of the cases from papers in this Special Issue: first, tabulation of key characteristics (Table 1), followed by extraction of key aggregate 'learnings' from their use. I then draw on several sources of theory to aid understanding of the enduring 'problem of implementation' of information systems. This construction builds on the sociotechnical conceptual framework for the DSS used by McCown (2002, this issue, Fig. 3) to open up the nature of the problem. This is followed by an analysis of the social dimension of DS intervention in which familiar approaches are categorised as four different strategies that span two technological intervention paradigms, again relating the theory to the case histories. This final section considers prospects for change in agricultural systems support for farmers' management, utilising lessons from the case histories and opportunities that seem to be provided by the new paradigm, new opportunities in the old paradigm, and the important fact that embracing the new does not require abandoning the successful aspects of the old.

\section{Interpreting nine case experiences}

The six case histories of DSS building and implementation in preceding papers, together with earlier papers on EPIPRE (Zadoks, 1989) and CALEX-Cotton (Plant,

\footnotetext{
${ }^{1}$ Throughout, I use 'ISD' to refer to Information System Development as the application of computers and telecommunications to managing and coordinating (Hirschheim et al., 1995, p. xi). The field of ISD includes DSS development and implementation. I also use 'DS' and 'IS' refer to 'decision support' and 'information system.'
} 
Table 1

Comparison of attributes of DSS cases

\begin{tabular}{|c|c|c|c|c|c|c|c|c|c|c|}
\hline \multirow[t]{2}{*}{ DS Product ${ }^{\mathrm{a}}$} & \multirow[t]{2}{*}{ Decision domain } & \multirow[t]{2}{*}{ Decision level } & \multicolumn{7}{|c|}{ DSS functions ${ }^{\mathrm{b}}$} & \multirow[t]{2}{*}{ Customer and delivery strategy } \\
\hline & & & 1 & 2 & 3 & 4 & 5 & 6 & 7 & \\
\hline 1. SIRATAC ${ }^{\mathrm{c}}$ & $\begin{array}{l}\text { IPM for irrigated cotton } \\
\text { management }\end{array}$ & Management control & $\mathrm{X}$ & & $\mathrm{X}$ & $\mathrm{X}$ & $\mathrm{X}$ & & $\mathrm{X}$ & $\begin{array}{l}\text { Centralised service by farmer-controlled } \\
\text { commercial company }\end{array}$ \\
\hline 2. CottonLOGIC ${ }^{c}$ & General cotton management & Management control & $\mathrm{X}$ & $\mathrm{X}$ & $\mathrm{X}$ & $\mathrm{X}$ & & & $\mathrm{X}$ & Freeware to farmers, consultants \\
\hline EPIPRE $^{\mathrm{d}}$ & IPDM for intensive wheat & Management control & $\mathrm{X}$ & & $\mathrm{X}$ & & $\mathrm{X}$ & & & Centralised government service; nominal fees \\
\hline GOSSYM/COMAX & Cotton management & Management control & $\mathrm{X}$ & $\mathrm{X}$ & $\mathrm{X}$ & $\mathrm{X}$ & $\mathrm{X}$ & $\mathrm{X}$ & & Sold to farmers via public extension \\
\hline 1. CALEX-Cotton ${ }^{\mathrm{f}}$ & Cotton management & Management control & $\mathrm{X}$ & $\mathrm{X}$ & $\mathrm{X}$ & & $\mathrm{X}$ & & $\mathrm{X}$ & Sold to farmers via public extension \\
\hline 2. CottonProf & Cotton management & Management control & $\mathrm{X}$ & & & & & & & Web-based freeware \\
\hline 1. WHEATMANg & $\begin{array}{l}\text { Wheat cultivar selection and } \\
\text { fertilization }\end{array}$ & Management control & & $\mathrm{X}$ & $\mathrm{X}$ & $\mathrm{X}$ & & $\mathrm{X}$ & $\mathrm{X}$ & Sold to farmers via public extension \\
\hline 2. WHEATMAN' ${ }^{g}$ plus & $\begin{array}{l}\text { Winter crop plant and } \\
\text { fertilization }\end{array}$ & Management control & & $\mathrm{X}$ & $\mathrm{X}$ & $\mathrm{X}$ & & $\mathrm{X}$ & $\mathrm{X}$ & Sold to farmers via public extension \\
\hline PCYield $^{\text {h }}$ & Soybean management & Management control & & $\mathrm{X}$ & & $\mathrm{X}$ & & $\mathrm{X}$ & & $\begin{array}{l}\text { Bundled in web-based commercial weather } \\
\text { service to farmers }\end{array}$ \\
\hline 1. GLA ${ }^{\mathrm{i}}$ & Grazing enterprise management & Strategic planning & & $\mathrm{X}$ & & $\mathrm{X}$ & & $\mathrm{X}$ & $\mathrm{X}$ & Federal resource agency contract \\
\hline 2. NUTBAL ${ }^{\mathrm{i}}$ & Animal nutrition management & Management control & $\mathrm{X}$ & & & $\mathrm{X}$ & $\mathrm{X}$ & & & $\begin{array}{l}\text { Fee for centralised service to farmers via } \\
\text { intermediaries }\end{array}$ \\
\hline 1. GrazFeed ${ }^{\mathrm{j}}$ & Animal nutrition management & Management control & $\mathrm{X}$ & & & $\mathrm{X}$ & $\mathrm{X}$ & & & Sold via software agent; intermediary \\
\hline 2 GrassGro $^{\mathrm{j}}$ & Grazing enterprise management & Strategic planning & & $\mathrm{X}$ & & $\mathrm{X}$ & $\mathrm{X}$ & $\mathrm{X}$ & & Commercial software agent; intermediary \\
\hline
\end{tabular}


Table 1 (continued)

\begin{tabular}{|c|c|c|c|c|c|c|c|c|c|c|}
\hline \multirow[t]{2}{*}{ DS Product ${ }^{\mathrm{a}}$} & \multirow[t]{2}{*}{ Decision domain } & \multirow[t]{2}{*}{ Decision level } & \multicolumn{7}{|c|}{ DSS functions ${ }^{b}$} & \multirow[t]{2}{*}{ Customer and delivery strategy } \\
\hline & & & 1 & 2 & 3 & 4 & 5 & 6 & 7 & \\
\hline \multirow[t]{2}{*}{$\begin{array}{l}\text { APSIM/ } \\
\text { FARMSCAPE }^{k}\end{array}$} & Cropping system management & & $\mathrm{X}$ & $\mathrm{X}$ & & $\mathrm{X}$ & & $\mathrm{X}$ & & $\begin{array}{l}\text { Commercial service via accredited } \\
\text { intermediaries }\end{array}$ \\
\hline & & Strategic planning & & & & & & & & \\
\hline
\end{tabular}

a Numbers represent successive DSS development efforts.

b $1=$ interprets enhanced system state measurement/description/forecast; $2=$ integrates diverse management factors; $3=$ uses qualitative rule base for interpreting inputs or producing outputs; $4=$ uses mathematical models for inferencing; $5=$ 'optimises' recommended action ('Makes decision'); $6=$ answers "what if?" questions; 7 = facilitates record keeping and/or formal reporting.

Hearn and Bange (2002)

d Zadoks (1989).

e Hodges et al. (1998).

${ }^{f}$ Plant (1997).

g Hayman and Easdown (2002).

h Welch et al. (2002)

Stuth et al. (2002).

${ }^{j}$ Donnelly et al. (2002).

k Carberry et al. (2002). 
1997; Goodell et al., 1993) and GOSSYM/COMAX (Hodges et al., 1998; Boone and Porter, 1997) provide documentation of efforts of scientists to make tools that are useful and used in farm planning and decision making. Table 1 sets out key features intended to aid sensible and helpful generalisations about what happened and what it might mean for the future.

The first column of Table 1, together with the caption, identifies the literature reference for the DSS cases. The second column names the DS products and numbers products in chronological sequence in cases of significant evolution or re-invention.

The fourth column distinguishes between levels of management. Most of these DS products address decisions at the level of management control $^{2}$; a few have been used in aiding strategic planning. Although ecological strategy is implicit in SIRATAC, CottonLOGIC, and EPIPRE, use in decision-making by farmers is in management control. GLA has a strategic planning orientation with focus on natural resource utilisation, and GrassGro and FARMSCAPE enable analysis of risk in strategic planning of structural changes to production systems. Management control takes the form of tactical planning (e.g. Hofstede, 1992) when control actions are complicated by high uncertainty about uncontrolled variables, such as rainfall.

The set of seven DSS Functions is an extension of the three recognized by Room (1979) and listed by Hearn and Bange (2002, p.2). DSS Function 1 relates to the derivation of some abstract property or representation of the system that has important meaning for management from input of some unconventional system description. Examples include using CottonPro or CottonLOGIC to derive a 'plant map' of a cotton crop from detailed description of the morphology of a sample of plants that would be made for no other management purpose. Similarly, the relative nutritional status of animals on low quality pasture is derived from innovative analysis of animal faeces with NUTBAL and from pasture description with GrazFeed. The distinguishing feature of this function is the high significance of a particular measurement in the DSS.

Function 2 entails more expansive use of a programmed logic, either as sets of rules (Function 3) or as mathematical models (Function 4). A powerful logic in an algorithm would seem to be necessary to provide sufficient 'potential usefulness' in risk assessment, including tactical forecasting (GOSSYM/COMAX and PCYield), identification of 'best practice' (Function 5), or in answering "what if?" questions (Function 6).

But it is clear that there are serious challenges to achieving in practice an algorithm's apparent potential usefulness. Its formal logic must be initialised and parameterised to represent real decision situations. Problem owners must be confident that the DSS specified to represent their problem situation is both adequate and its specification affordable in terms of non-routine local information. PCYield was designed to minimise this problem by using stratified generic inputs; GrassGro uses generic templates for typical situations to reduce operating costs. In FARMSCAPE,

\footnotetext{
${ }^{2}$ Anthony (1965) distinguishes between 'strategic planning' and 'management control', but recognises that in practice, within the latter, operational control and short term (tactical) planning are inseparable (p. 11). "The captain of a ship is involved in management control"' (p. 31).
} 
early usefulness and acceptance was achieved only with investment in local specification to the field level, but templates are used where sufficient or necessary.

Several important general points can be made about the collective experience:

1. Gaining entry to farm management practice for a DSS has proved far more difficult than envisioned. Researchers have undergone unanticipated ordeals in their attempts to make their research useful to farming via their DSS. This is agriculture's 'problem of implementation.'

2. There has been a shift away from an emphasis on algorithmic optimisation of outcomes - of DSSs 'making decisions' - to aiding farmers in their decision processes, a need identified by Malcolm (1990, p. 40). A corollary of this has been a shift by DSS builders away from a premium on comprehensive representation of complex tasks/problems. Plant (1997) is admirably candid about the mistake in assuming DSS 'comprehensiveness' in CALEX-Cotton was the key to potential usefulness. They learned from painful experience that farmers preferred operational tools dealing with a small 'control' matter that could be run, preferably, before leaving the field (see Point 5).

3. Even when a DSS is adopted, farmers strive to achieve the designed benefit with minimal use of the formal instrument. Instances of learning from the DSS decreasing the need for continued use are reported in the stories of SIRATAC, CottonLOGIC and WHEATMAN.

4. There is no indication of any incentive to persist with expert system technology for decision support. This is most dramatically illustrated by the CALEX-Cotton case, but also by those of SIRATAC, and GOSSYM/ COMAX.

5. Concomitant with these trends is the tendency to portray the farmer as a tool user capable of learning and skill development rather than as a traditionalist in need of an external prescription for action to get the right outcome in the face of overwhelming complexity. DSSs as tools contribute mainly in management control by enabling exploitation of new knowledge of the state of a situation, e.g. animal diets (NUTBAL, GrazFeed), detailed weather including forecasts (e.g. PCYield, WHEATMAN, FARMSCAPE), crop structure (e.g. CottonLOGIC, CottonPro), soil water and $\mathrm{N}$ (e.g. WHEATMAN, GOSSYM/COMAX, and FARMSCAPE). But there are also cases of DS products and services being important aids to farmer learning and skill development (e.g. GrazFeed, NUTBAL, WHEATMAN, FARMSCAPE).

6. High participation of farmers or intermediaries in ISD has not consistently resulted in high subsequent use. This is complicated by both the variation in whether the software is used by farmers or by intermediaries and by the nature of 'participation' (as differentiated in Section 5).

7. There is a trend toward delivering benefits of models to farmers via intermediaries with the computers (GLA, GrassGro, and FARMSCAPE are used by intermediaries exclusively, while CottonLOGIC, NUTBAL, and 
GrazFeed are also used by farmers). This is a return to a mode of using models to aid management that preceded the DSS, whose 'problem of implementation' the DSS was expected to overcome (McCown, 2002).

Most of these points will re-emerge within a theoretical context in the following two sections.

\section{The 'problem of implementation'}

\section{1. 'Use' criteria for judging DSS performance}

The generally disappointing uptake of computerised decision support by farmers must be seen as a special case of more general problems of adoption and diffusion of information technology which utilise computers and telecommunications in information systems development (ISD) (Hirschheim et al., 1995). Of particular relevance to the agricultural DSS case is the 'problem of implementation' experienced by the Operations Research/Management Science (OR/MS) movement (McCown, 2002) and, subsequently, that experienced by DSSs in business and industry. Two decades of research on problems of user resistance to ISD in organizations has produced social science models that that are purported to explain much of the adoption/non-adoption behaviour (e.g. Davis, 1989, 1993). Similar to reports in the earlier OR/MS literature, failures of ISD are found to be not mainly about technology, but about the interface ${ }^{3}$ between the technology and human users. It has become increasingly clear that of the two variables long recognised as key to user acceptance, i.e. perceived usefulness and ease of use, by far the more important is the former - the relationship between the tool and the user's purpose, or task (e.g. Keil et al., 1995; Davis, 1993). This finding provides a sound rationale for shifting efforts to explain the agricultural DSS 'problem of implementation' away from computer ownership and farmer computing expertise to the substance of what is offered to a farmer in a DSS and its usefulness in improving the conduct of the decision task or alleviating the problem.In drawing upon the literature, which concerns DS in large organisations almost exclusively, it is important to position the relatively simple organization of the family farm in relation to the appropriate element of the large hierarchical organization. Criteria of usefulness of a DSS to a farmer can be expected to be quite different to the middle level manager in an organization comprised of multiple layers of decision-making and accountability. In this, its corporate homeland, the DSS innovation emerged as a little chunk of bureaucracy that serves a role that is, at least subtly, regulatory. But in being 'one's own boss,' a family farmer's decision to use (or not) a DSS is entirely voluntary. As a manager, the farmer may be more comparable to the corporate senior executive, who has a well-documented history of non-use. To be used by such decision makers, who enjoy high degrees of

\footnotetext{
${ }^{3}$ An interface that encompasses not just that between the computer and the user but between those who build the system and those who use it.
} 


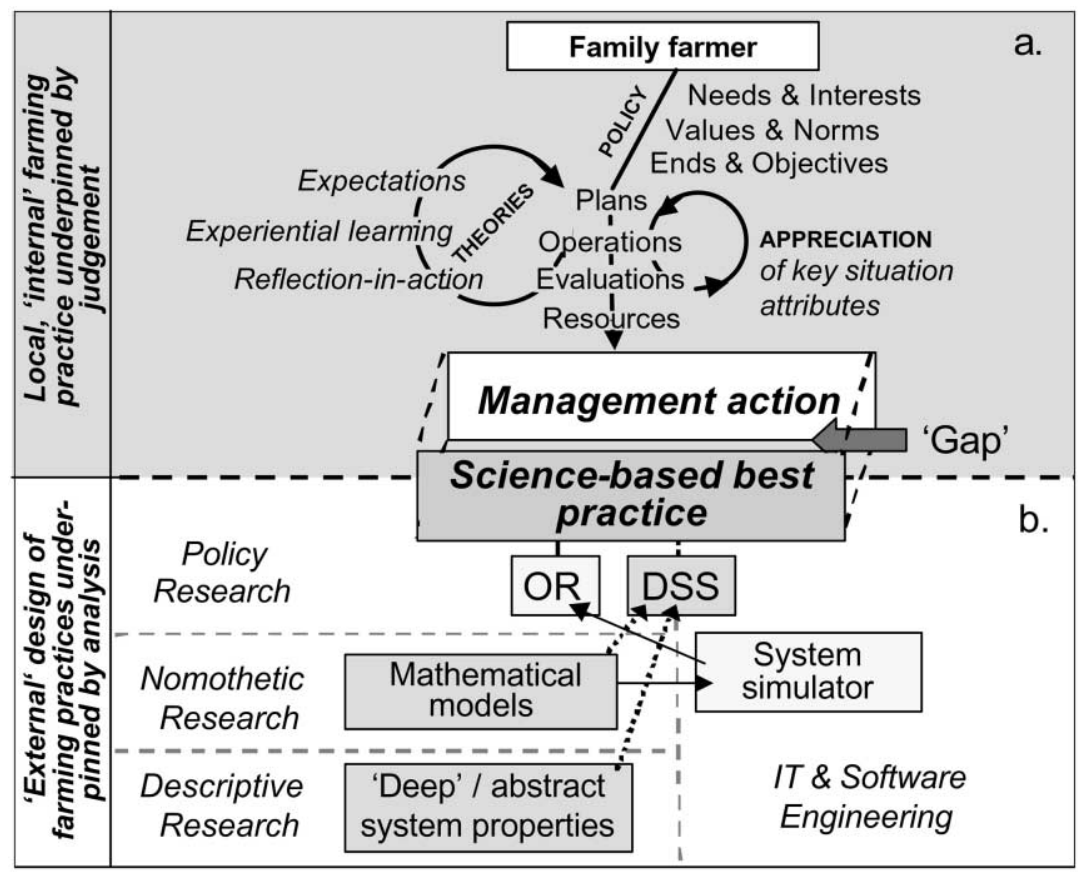

Fig. 1. 'Internal' (a) and 'external' (b) processes for planning and decision-making. (Policy research identifies what action ought to be taken based on formal analysis and expert knowledge, i.e. it is normative.).

freedom to chose (discretion) and power to act (agency), a DSS must have high value in enhancing the manager's decision process as well as carry tolerable costs and risks. Fig. 1 is an attempt to shed light on why these conditions are so rarely met in normal farm management practice.

\subsection{Theoretical analysis of IS 'usefulness' in management practice of a family farm}

\subsection{1. 'Internal' and 'external' approaches to structuring farm management action}

Fig. 1 juxtaposes two competing approaches to structuring practice, one local and 'internal' to the specific farm, and the other 'external' and designed according to scientific understanding of the type of production system and the idealised, assumed goals of the farmer. The discrepancy between 'Science-based best practice' and 'Management Action' is intended to depict the infamous 'gap' between IS theory and practice (e.g. Howard, 1963).

Situated practice (Fig. 1a) is purposeful action set in a material and social/behavioural context (Suchman, 1987, p. 50). Everyday activity in the normal social practice of farming tends to be conducted 'automatically' in reaction to correspondence between expectations and outcomes when environmental circumstances are within the 'normal' range (Dreyfus, 1991, p. 4). This represents robust adaptation of management process because expectations have been shaped by what has worked 
satisfactorily in the past. But periodically, management process must change due to new inadequacy of old process. This change may be adaptation to changes in the environment or it may be required to take competitive advantage of new technology. Much of modern management theory concerns such dynamic management change (e.g. Senge, 1990). Fig. 1a represents what seems to go on 'inside' a situated human decision-maker, drawing from the ideas of the social scientists and philosophers Oquist (1978), Schon (1983), Suchman (1987), and Popper (1972). This construct seems to apply to personal practice within a community of social practice irrespective of whether the decisions are those of farmers raising crops or agricultural scientists raising children. Farms and households are 'open' systems, only partly deterministic, with many activities amenable to structuring only by the problem owner's policy, experience and on-the-ground appreciation of the situation (Fig. 1a). This decisionmaking behaviour is often described as 'intuitive' and 'subjective' because it is 'internal' and inaccessible to observers. Because this judgement making is experienced as part of normal living, the decision maker is largely unaware of 'being structured.' According to Senge (1990), in moving beyond behaviour that is merely 'reactive' in the face of change in circumstances, the first resource to be tapped is the structure of patterns of past experience. Thus 'theories of action' (Fig. 1a) can enable 'responsive' practice to "begin to break the grip of short-term reactiveness. At least they suggest how, over a longer term, we can respond to shifting trends" (Senge, 1990, p. 53). But Senge's main thrust concerns the value of determinant structure over patterns of past events.

The reason that structural explanations are so important is that only they address the underlying causes of behavior at a level that patterns of behavior can be changed. Structure produces behavior, and changing underlying structures can produce different patterns of behavior. In this sense, structural explanations are inherently generative. Moreover, since structure in human systems includes the "operating policies" [e.g. Fig. 1a] of the decision-makers in the system, redesigning our own decision-making redesigns the system structure (Senge, 1990, p 53. My emphasis and interjection).

Senge's responsive practice, based on experienced patterns, is an 'internal' analogy to the 'external' science practice of drawing inferences from statistical relationships; his use of generative structure is analogous to external cause-effect theory.

The second type of practice, represented in Fig. 1b, offers structure of the external environment. Possibilities stem from the activities of three types of researchdescriptive, nomothetic, and policy research (Oquist, 1978) depicted in McCown (2002, Fig. 2). Scientific knowledge is enhanced and communicated by the information technology used in a DSS or system simulator used by an intermediary (OR). Nomothetic research provides mathematical models of the material system of the managed enterprise. Policy research uses these models to simulate alternative means to carry out a typical farmer's policies, e.g. optimising returns, minimising pesticide use, minimising soil loss, etc. (what a rational farmer ought to do to achieve the policy goal with reference to the value of 'efficiency'). 


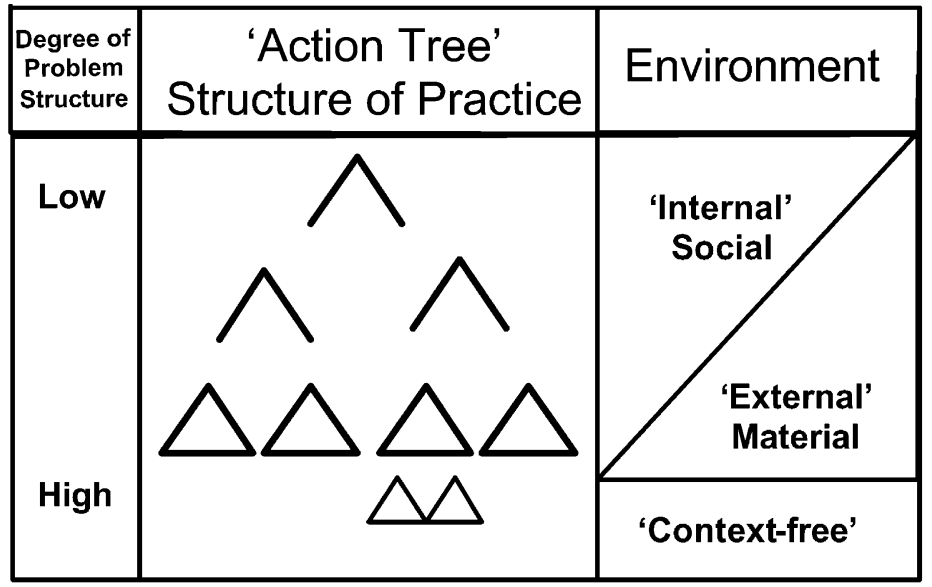

Fig. 2. Factors in the milieu of a DSS that influence its adoption and the nature of 'adoption'. (Closed triangles represent 'technical' actions; open triangles represent 'practical' actions. Action types defined in Table 1.)

Among scientists and engineers, a prevalent rationale for a DSS has been that it puts farm decision-making on a more rational footing by utilising specialist knowledge of the 'deep' structure of the systems and problems that are simply not accessible in situated practice. Ways in which this might be helpful can be derived from a list of ways that Hofstede (1992, p. 17) found situations to be problematic because of lack of structure:

1. Deficient definition of the system in terms of relevant objects and their environment,

2. Unknown initial states,

3. Unclear goals,

4. Constraints soft or unknown, and

5. Consequences poorly predictable.

A science-based DSS or system simulator has a programmed 'logic' of the material situation which is based on science: a system structured with relevant entities (1 above) and interacting systematically to predict consequences of events and actions ( 5 above) enabling calculation of relevant probabilities of some uncertain constraints (4 above). As such, a DSS is offered as a tool for 'rational' inference-making in the hope that it proves useful in reducing these management uncertainties.

But claims for the importance of the DSS and the expert system to providing task and problem structure have been found to be overstated. In the 1970s and 1980s, the theoretical rationale for 'support' was congruent with the, then, vigorous discourse in cognitive science that claimed that the minds of ordinary human managers were not well equipped to deal with the enormous complexity of the systems they managed and that, because brains and computers processed information similarly, computers could 'help farmers make more rational decisions.' But in recent years 
this symbolic information-processing view of human cognition has been largely replaced by the more 'ecological' theories of 'situated cognition,' 'situated action,' and 'activity theory' (e.g. Johnson and Erneling, 1997; Suchman, 1987; Clancey, 1997; Nardi, 1996) in which there is an emphasis on sense-making and experiential learning in complex, lived-in environments. This represents a drastic shift away from a focus on farmer need for external logic to a focus on learning-in-action. But it takes some time for such change to replace old tendencies to think of farmers primarily as technicians, increasingly handicapped by a lag in appropriate information technology, as indicated by the following recently published passage.

The agricultural knowledge base in particular is growing rapidly, as science improves its understanding of biological and chemical processes, and the quantity of data can be overwhelming. Filtering and assimilating this mass of information is a formidable task particularly given the limitations of human processing. Unlike a computer, we cannot manipulate many things in our heads at one time and we are known to make errors in logical thinking. We are also limited in the quantity of new information we can easily absorb. [...] DSSs, by providing pre-filtered information in the form of simulation models, coupled with the capability of performing many hundreds of calculations a second, offer a potentially useful way of increasing the effectiveness of on-farm decisionmaking. [...] Farm decision-making is made up of many interlinked decisions... It is this balancing act, with more than a head full of data, in which computer based decision support can be useful (Parker, 1999, pp. 275, 279. Original emphasis).

This statement contains the misconception that although 'practice' in farming decision-making may be of two kinds, as depicted in Fig. 1, the 'gap' between them has a technological solution. For Parker, improved decision making by a farmer requires information processing beyond normal capabilities in situated practice, and made possible by computerised decision support. But as Dreyfus (1994) points out, the problem of burgeoning scientific data is normally solved by a situated practitioner using a quite different 'structuring' strategy.

A computer can help by supplying more facts than the manager could possibly remember, but only experience enables the manager to see the current state of affairs as a specific situation and so to see what is relevant. That expert knowhow cannot be put into the computer by adding more facts...(Dreyfus, 1994, p. xlii. My emphasis).

This distinction between Parker's 'more than a head full of data' and Dreyfus' 'what is relevant' is the distinction between 'knowing that' and 'knowing how' Ryle (1949) and depicted in Fig. 2 of McCown (2002, this issue).

Despite theoretical misconceptions that have exaggerated farmers' need for scientific structuring of problems and information, there remains the historical fact that there are times when scientific structuring has been extraordinarily helpful in farm 
problem solving. And while these may be the times when "nothing is so practical as a good theory," as expressed in the epigram following the title of this paper, even a good theory may not spare us the consequences of our assumptions made in applying the theory. This leaves a manager with three perplexing questions when presented with a DSS. First, does the model of relevant objects and their environment (point ' 1 ' in Hofstede's list earlier) plus relevant constraints (point ' 4 ') map onto the farmer's system well enough to provide a significant contribution to calculation of consequences (point ' 5 ')? In other words, is the theoretical or statistical logic in the model an adequate 'logic of the situation' (Checkland, 1978)? Second, do assumptions made in the modelled system regarding system properties and initial conditions render the DSS insufficiently relevant to the farmer's system for the DSS to be useful? In other words, is the 'logic' adequately contextualised? Third, to avoid risk of wrong assumptions, is it technically and economically feasible to provide local information to specify the modelled system to adequately represent the local properties and initial conditions of the farmer's current system? In other words, is acquisition of local data to ensure relevance practicable?

\subsection{2. 'Learning' to reduce uncertainty: a bridge between the external and the internal}

The DS efforts in Table 1 vary greatly in their strategies in relation to these questions that affect relevance to local decision-making and eventual use of the product. Many things have been tried. But the enigma remains: why, in these cases and more generally, after 25 years of DSS 'push' does routine use of the DSS in their decisionmaking by computer-using farmers remain so low. However, this generalisation disguises the fact that some DSSs have been used by some farmers in some way for some period of time. Not only does this provide a modicum of satisfaction and encouragement to DSS workers, but also in these patterns (and others like them outside of agriculture) may lie considerable potential for learning how to more effectively provide scientific support for management.

The often-stated problem faced by farmers for which it is expected that a DSS might prove useful is that of overwhelming complexity of factual information (e.g. Parker quote above). But one of the profound realisations that has accompanied the 'situated cognition' revolution has been that the effect of complexity is secondary to uncertainty. Situated practice evolves largely as successful responses to uncertainties.

Decision problems encountered in everyday life are invested with uncertainty; if this were not the case, they would not have been conceptualized as problems in the first place. [...] From an evolutionary standpoint, humans can be seen as seeking to reduce uncertainty. Uncertainty as such creates stress that, being undesirable and dysfunctional, will necessitate its own conditions of resolution. Trial and error and the use of feedback constitute attempts to reduce uncertainty by acting on the world. Another coping mechanism is that of treating uncertain parts of the decision problem as certain, determined by the agency one feels one has in acting upon the world (Humphreys and Berkeley, 1985, p. 257-258). 
Rogers (1995, p. 35) similarly identified uncertainty as the key issue with regard to implementation of science-based/information technology (Fig. 1b) such as a DSS: the prime role of the intervention is reduction of uncertainty in the cause-effect relationships involved in acting to achieve a desired outcome. But as is related in a number of the cases, there is an important temporal dimension to uncertainty in management.

It is often found that the interest of a farmer who comes to appreciate the value of model-based intervention in practice dissipates after a period. This has been interpreted as the result of farmers learning from the DSS and then no longer needing the formal aid, e.g. SIRATAC (Hearn and Bange, 2002) and WHEATMAN (Hayman and Easdown, 2002). A DSS or external recommendation may provide a useful start in a new situation, but as Humphrey and Berkeley point out (above quote), learning is progressed through 'acting on the world,' by trial-and-error and the use of feedback. This point is also illustrated by Dreyfus (1994) in describing the process of transition from the external rules of practice to new situated, internal practice:

...skill acquisition. . .usually begins with... applying rules or manipulating context-free elements. [...] After one begins to understand a domain, however, one sees meaningful aspects, not context-free features. [...] At the next stage, a competent performer learns to set goals and then look at the current situation in terms of what is relevant to achieving those goals. A further stage of proficiency is achieved when, after a great deal of experience an operator is able to see the situation as having a certain significance tending toward a certain outcome, and certain aspects of the situation stand out as salient in relation to that end. Finally after even more experience, one reaches the level where one sees immediately what must be done. [...] There is no reason to think that the rules that play a role in the acquisition of a skill play a role in its later application (Dreyfus, 1994, p.xii. My emphasis).

In addition to the use pattern related to a specific learning history, there is a periodic use phenomenon illustrated by the response of a farmer to my question to him, "Why don't farmers use DSSs more?" Answer: "You need a doctor when you're sick but not when you're well." Carberry et al. (2002) report that farmers' interest is high when they are wrestling with a change and the new uncertainties change brings. This suggests that when the interventionists are equipped to deal with a wide range of farming issues, a farmer's use history can be expected to be a series of use periods distributed in time, each trialling a specific management change, and each with a unique learning history.

\section{The 'problem of implementation' enlightened by 'the nature of action'}

\subsection{The significance of distinguishing between practical and technical actions}

In analysing the place (or not) of computers in decision-making, Collins and Kusch (1998) distinguish between what they term 'mimeomorphic' and 'polimorphic' 
actions. These two concepts are at the heart of the theory that they create for the place of intelligent machines in human social practice. Although these concepts are original and ingenious, their unfamiliarity and need for explanation challenge space limits here. Instead, I have judged that the dichotomy of 'mimeomorphic' and 'polymorphic' actions correspond sufficiently well to the more familiar dichotomy of 'technical' and 'practical' rationalities for practice 4 (e.g. Ravetz, 1971; Flood and Ulrich, 1991; McCown, 2002). Table 2 draws on Collins and Kusch (1998) and Flood and Ulrich (1991) to highlight differences between 'technical' and 'practical' especially salient to DSS implementation. Both behaviour types are 'actions' because they are motivated by the intentionality of the manager, which in conjunction with the manager's policy, constitutes practice (Fig. 1a). "Practice is policy and action in the context of determinate structures and processes" (Oquist, 1978, p. 145). The 'action tree' of Fig. 2 reflects the structuring of practice by policy in Fig. 1a. In Fig. 2, the most highly structured technical actions are found at the base of the 'tree,' and are quite unaffected by social, or even material, context. Technical actions higher in the action tree appear less structured to the outside observer, are 'imbedded in' higher level practical actions (Collins and Kusch, 1998, p. 51), complicated by contexts which include considerations of practical/social values. Towards the top of the 'action tree' the internal social determinants dominate, and the practical actions appear ill-structured from the outside (Fig. 2).

This individual behaviour originates in a worldview about human needs and purposes that constitutes a set of meanings shared within a culture (Flood and Ulrich, 1991, p.193). What managers in a (farming) culture actually do and how they talk about it is profoundly influenced by these shared meanings.

DSS work is focused on technical action, and DSS builders have been content to condense the social/practical component into simple assumptions (McCown, 2002). Better understanding of our present crisis of implementation may now depend on using insights such as those contained in Fig. 2 and Table 2 to 'tease out the consequences of our assumptions', as per the much-referenced epigram from Simon (1996) which precedes this paper.

To the degree that information systems (DSS and system simulator, Fig. 1b) change or replace a process of deliberation and judgement making (Fig. 1a), intervention has had practical, i.e. social, as well as technical, impact. Such an influence and its acceptability to the decision maker can be discussed in terms of whether the IS functions as a tool that enhances the decision maker's process or as a proxy - a

\footnotetext{
${ }^{4}$ Technical basis for practice: "According to the model of technical rationality - . . activity consists in instrumental problem-solving made rigorous by the application of scientific theory and technique" (Schon, 1983, p.21).

Practical basis for practice: "A vocation is the antithesis to a profession because it is based upon customary [functionality institutionalized in culture] activities and modified by the trial and error of individual practice (Schon, 1983, p. 22).

"The capacity for [technical] control made possible by the empirical sciences is not to be confused with the capacity for enlightened action [practical rationality]. The scientific control of natural and social processes - in one word, technology - does not release man from actions. Just as before, conflicts must be decided, interests realized, interpretations found..." (Habermas, 1971, quoted by Ulrich, 1991, p. 260).
} 
Table 2

Distinctions between technical actions and practical actions

\begin{tabular}{|c|c|}
\hline Technical action ( $\triangle$ in Fig. 2$)$ & Practical action $($ Technical + Social $)(\wedge$ in Fig. 2$)$ \\
\hline $\begin{array}{l}\text { Purposeful behaviour that varies with external, } \\
\text { material context. }\end{array}$ & $\begin{array}{l}\text { Purposeful behaviour that varies with internal } \\
\text { social context as well as external, material context. }\end{array}$ \\
\hline $\begin{array}{l}\text { Using task structure, action can be explained } \\
\text { by those with access to knowledge of the } \\
\text { intention plus the environmental conditions. }\end{array}$ & $\begin{array}{l}\text { Action can be understood fully only by others } \\
\text { who share the culture. }\end{array}$ \\
\hline $\begin{array}{l}\text { Optimal action can be designed in terms of } \\
\text { 'fit' to the external environment. }\end{array}$ & $\begin{array}{l}\text { Nature of the (internal) environment normally } \\
\text { defies analysis and prediction of actions. }\end{array}$ \\
\hline $\begin{array}{l}\text { Procedural rules can adequately enable delegation } \\
\text { of a task. }\end{array}$ & $\begin{array}{l}\text { Procedural rules never adequate for delegation } \\
\text { to anyone outside the 'community of practice'. } \\
\text { Rules mainly concern what counts as a mistake } \\
\text { in the community of practice. }\end{array}$ \\
\hline Can be modelled in a computer. & Defies being modelled in a computer. \\
\hline $\begin{array}{l}\text { Technological intervention depends on } \\
\text { demonstration of sufficient instrumental value. }\end{array}$ & $\begin{array}{l}\text { Technological intervention depends on } \\
\text { achievement of mutual understanding of } \\
\text { 'problem' and appropriate 'process'. }\end{array}$ \\
\hline
\end{tabular}

substitute-for existing decision process. But the difference between a tool and a proxy is far from absolute, and it is relative to both the position of the IS innovation in the action tree and the vantage point in the tree from which the innovation is evaluated.

The general rule is that we can always turn a tool into a proxy by taking a lower vantage point, and we can always turn a proxy into a tool by taking a higher vantage point (Collins and Kusch, 1998, p. 120).

In a hierarchical corporate organization, where there is a stable action tree structure in which positions in the tree represent different people as well as different roles, the vantage point of the CEO is always from the top. In family farms that seriously consider an IS for management there is also, commonly, multiple 'levels' in the farm firm structure. Family members and outside service providers perform roles that can generally be viewed as conduct of tasks delegated to lower levels in the action tree. But in contrast to the corporate manager, for the family farmer, the role and, correspondingly, the vantage point in the action tree for viewing a DSS innovation changes as (s)he moves between the 'owner/managing director' role at top of the action tree and hands-on technical tasks at the bottom of the tree.

\subsection{The significance between the DSS as 'tool' and as 'proxy'}

How can Fig. 2 shed light on why a DSS might succeed or fail to be useful to or used by a farmer? A successful DSS 'fits' somewhere in the tree representing practice structure at a level at which the role (proxy or tool) suits the manager's needs and aspirations for system function. The environment low in the action tree is dominated by technical concerns, and the relationships between actions and outcomes (task 
structure) are relatively well defined. The main function of a DSS used as a tool is to relieve task uncertainty. Most agricultural DSSs are designed as tools to enable more rational (structured) choice of low-level technical actions. From the manager's perspective, because these technical actions "can be delegated to entities that do not understand [social] context but work according to plans, the lower levels of action trees can often be delegated to tools" Collins and Kusch (1998, p. 52 footnote). But these authors go on to provide a possible explanation for why these tools, while relevant, have often not been judged by farmers to be useful.

The reason nearly all actions terminate in [technical] actions is that as we go down the tree structure, we reach ever more precisely specified action types, and almost inevitably we cease to care how these already highly specified actions are further specified. We cannot care about the exact way we carry out the most minute elements of our actions...(Collins and Kusch, 1998, p. 54).

Farmers cease to care about (even relevant) tools when they can't see sufficient practical value for action resulting from the output, taking into consideration the costs, including managerial time and attention.

But where technical action low in the action tree is strongly influenced by environmental uncertainty rather than task uncertainty, e.g. current stored soil water, feed quality, or crop pest density, the level of 'care' about local structural detail can be high. When this is the case, a DSS tool that is designed to accommodate local environmental information that 'situates' its logic for tasks may be seen as useful for practice. Some IS tools that feature a novel or superior scientific logic prove to be valuable in practice irrespective of environmental circumstances because their performance is not strongly context-dependent (centre, Fig. 2). For example, output of tools such as cotton 'plant mapping' software and feed ration computation using formal 'feeding standards' (e.g. GrazFeed) are largely unaffected by the external environment.

In contrast to a tool, the DSS functioning as a proxy replaces expert process in a decision task, at least in part. Among types of DSS (McCown, 2002, this issue, Fig. 3), i.e. decision analysis, expert systems and decision calculus, the expert system and decision analysis are overt proxies for decision process. In agriculture, the expert system seems to have had a relatively ephemeral life compared to the modelbased decision calculus type or a complex, versatile simulator, both of which deal only with the external environment of the decision. In the introduction to a review of expert systems in agriculture that appeared to him to be 'viable', Jones (1989) noted that in the period from 1985 to 1988 , considerable success with expert systems was achieved in the commercial sector by focusing on "well-defined, narrow-domain problems." He further observed that in the same period, in agricultural research, interest and expectations that began high, declined, due partly to a preponderance of rhetoric about theory over achievements in practice. Two of the cases that Jones considered to be 'viable' were CALEX-Cotton and GOSSYM/COMAX. Neither of these focused on "well-defined, narrow-domain problems," and we can now see that the judgement of 'viable' was premature. 
Plant and Stone (1991, p.xi) first justify work on expert systems as proxies for expert professional advisers on the grounds that such people and their time are scarce. The computer proxy was "intended to be widely disseminated to individuals who lacked the expertise experts provide." Later they tend to resort to the farmeras-cognitive-cripple discourse as grounds for the expert system as a proxy for situated farmer experience in times of change.

...in the face of all the complexity and uncertainty implied in farming, it is clearly unreasonable, if not impossible, for a farmer to acquire and apply all this knowledge each time a pest management decision is made. Instead, farmers develop heuristics, rules of thumb that help them made difficult decisions. These rules of thumb take the place of a systems-level understanding of all the complex interactions affecting crops and livestock. Over time, heuristics are tested using a kind of natural selection. [...] as agriculture changes and new technologies emerge, heuristics must change as well. It is not practical to require farmers to learn purely from experience. Research must provide not only new technology but also new heuristics (Plant and Stone, 1991, p.9).

Richard Plant had led in designing and building the expert system, CALEXCotton. According to Plant, the product provided "a software package that can be used by growers, pest control advisers, consultants, and other managers for overall agricultural management decision support" (Plant, 1989, p. 50; my emphasis). "The object was an integrated program that would provide comprehensive support for crop management decisions." (Plant, 1997, p. 34) - a radical departure from Jones' (1989) 'well-defined, narrow domain problems' where expert system success had been experienced. Yet, Jones, himself, felt that the CALEX concept was "a very powerful idea and in practice it could be a revolutionary software tool" (p. 14). Ten years later, in one of the most substantial published critical reflections on a major DSS experience, Plant (1997) reported on the fate of CALEX-Cotton. After 5 years, of 145 registered users, 15 were still using the program. This report on the demise of CALEX and the relative success of two simpler derivative programs suggests two lessons: (1) to be used a program must provide a significant net benefit to the decision maker's internal process, i.e. be a tool rather than a proxy and (2) it is more important that the tool be useful in the process than to be comprehensive. Significantly, the notion of a high level proxy for an expert adviser or farmer, so prominent in Plant and Stone (1991), was gone.

According to the theory depicted in Fig. 2, a DSS proxy can be implemented successfully if it replaces decision action in the "well-defined, narrow-domain problems" near the bottom of the action tree. GOSSYM is a complex model that requires considerable scientific expertise to set it up to represent a situation and to interpret its results. COMAX was an artificial expert in setting up and interpreting GOSSYM to which these tasks low in the action tree could be 'delegated' by farmers and advisers.

Attempts to implement a DSS high in the action tree can be expected to be problematic in a family farm organization. This is because such an attempt causes a 
"shift in the locus of control from the human tool user to the tool," thereby tending to make it a proxy (Collins and Kusch, 1998, p. 52, footnote 14). Nothing characterises the family farmer as a manager more than values concerning discretionary freedom, agency, and opportunity to display good judgement (Mooney, 1988; Frost, 2000; Gasson, 1973). Although DSS proxies can be implemented high in the action tree by radical change of tasks and roles where hierarchical organisational structure channels such transformation (Berg, 1997), in Western family farming, intervention goals can be achieved only through "inducing voluntary change enhanced by satisfying client goals" (Roling, 1988, p.38). As pointed out earlier, this emphasis on the combination of (1) the high value that experienced managers place on their decision process and (2) the personal agency that enables the protection of their process is reinforced by evidence that senior corporate managers have similar behaviours to family farmers with regard to their delegation to DSSs.

SIRATAC was, functionally, an expert system. That SIRATAC suffered the problem expected of a proxy high in the action tree of family farming is evidenced by the report that SIRATAC's most staunch supporters were managers of corporate farms, who appreciated its value in standardizing and regulating management among their multiple farms and farm managers and in training new agronomists (Hearn and Bange, 2002).

\subsection{Solution for the 'solution': going back to intermediaries with models}

The DSS as a solution for the 'problem of implementation' in OR/MS was based on the notion of a 'computerised staff assistant' (Keen, 1987, p. 287) or an 'artificial expert' (Collins, 1990; Collins and Kusch, 1998, p. 14; Humphreys and Berkeley, 1985, p. 263) replacing a human expert with a computer model (McCown, 2002). From several of the cases in this Special Issue, we see a trend to address the problem of implementation of the DSS by returning to delegation to human providers of computer-dependent information services. Successful senior managers in corporations or farms must delegate tasks, and it is obvious that a task's candidacy for delegation is closely related to its position in the action tree vis-a-vis the manager. In some production systems, there is a trend towards increased delegation of technical and accounting tasks to private consultants. A number of cases in this Issue (GLA, NUTBAL, GrassGro, CottonLOGIC and FARMSCAPE) concern an IS that features intermediaries with DS products servicing the needs of client farmers, a phenomenon in the corporate world described by Martin and Clarke (1990).

...instead of accessing information systems directly, top managers are usually assisted by intermediaries who provide the necessary data access and technical skills. [...] as managers move up the organisation they tend to rely more on other people to access information systems for them, the intermediaries acting as information system 'chauffeurs' for their senior colleagues. A crucial point is that top managers who avoid using computers interactively may be doing so for very good reasons. [...] Good access to experts... may make interactive perso- 
nal use of IS technology by the top manager himself unnecessary, or even unattractive - a case of keeping a dog and barking oneself (p. 28)

Any widespread analogue for this phenomenon in farm management depends on the prospects for farmers doing the 'barking' and consultants willing to modify their practice and/or role. In a number of the case stories, use of the DSS by intermediaries is reported to be important to farm decision making. Although advisers have been identified by others as preferable targets to farmers for this technology, this newly directed 'push' is more conspicuous than any market 'pull' from this sector.

Carberry et al. (2002) reports on a still developing case that set about to test the feasibility of combining flexible, situated simulation delivered by researchers acting in the role of commercial consultants as a type of 'action research' (McCown, 2002, this issue, Fig. 2). Farmers with a new appreciation of the value of situated simulation articulated a willingness to pay for a commercial service. This potential market is providing the incentive for consultants to gain the required expertise to earn their keep from farmers with a new, developing IS-backed 'bark'.

\section{The importance of intervention paradigm}

\subsection{Shifting focus from farm management action to DSS intervention action}

Intervention in family farming practice with an IS, such as a DSS or a simulator in 'what if?' discussions, depends on the extent farmers see the innovation serving their interest or on their willingness to be persuaded. Whether the interventionist is motivated to bring about change in decision practice for the greater good of an industry or of a society or to assist farmer clients in achieving their personal objectives, the means available are dependent solely on the inherently weak process of communication (Roling, 1988, p.43). This suggests that success might depend importantly on the relationship between the interventionist and the farmer. This relationship was the theme of a contribution to this field by the management scientists, Churchman and Schainblatt (1965a), in a, now, classic paper entitled "The researcher and the manager: a dialectic of implementation."

We shall use the term "implementation" to refer to the manner in which the manager may come to use the results of scientific effort. The "problem of implementation" is the problem of determining what activities of the scientist and the manager are most appropriate to bring about an effective relationship

(Churchman and Schainblatt, 1965a, p. 71. My emphasis).

They perceived four types of relationships between scientists-with-their-modelsabout-management and practicing managers. The following briefly describes each of these, with minor adjustments made to update them to include manager-operated DSSs and to adapt the language to the domain of agriculture. The first type of relationship is that of 'separate-function,' in which the role of the DSS worker is to 
adapt models to be useful and useable in improving practice or solving problems that are amenable to formal treatment in computer software. The scientist hopes that the DSS will be adopted and used widely, but except for making the package as easy to use as possible, it is accepted that this is really beyond the builder's control. Success is taken to depend on the scientist understanding the technical problem and technological solution. By this relationship,

"...implementation" is the process of translating the theoretical solution into an "operational" solution. [...] The separate-function position, attractive as it is to the technologists, simply ignores the heart of the problem of management science, namely, the relationship to be established between the manager and scientists. At best this position argues that the relational problem is easy, namely, a "translation" of technical findings into "simple" terms (Churchman and Schainblatt, 1965a, pp. 74, 82),

Whereas this first type of relationship is essentially no relationship, the second entails 'the farmer coming to understand the scientist', i.e. the farmer coming to understand how the management problem or task is structured and modelled by the scientist and how this might be relevant to his/her own management. Churchman and Schainblatt (1965a) referred to it as the 'communication,' or 'education,' relationship.

For the proper communication to take place, the manager must understand what the scientist is trying to do and why he does what he does. Here the problem of implementation is the education of the manager. After a successful implementation, the manager himself becomes "more of a scientist [in his practice] (p. 73).

Advocates for the third relationship argue that it is simply not practical for managers to understand the scientific viewpoint; instead, scientists must improve their understanding of the farmer and his/her practice in order to overcome resistance to the DSS on offer.

...we label this group the persuaders: their attitude is not too different from that of market researchers who see their task to be one of learning enough about consumers to "sell" them. Here "implementation" means the process of 'selling' the manager on the validity of the scientist's approach (p. 73).

Churchman and Schainblatt (1965a) considered that "The communication and persuasion positions...together...pose the critical problem, but they must be extended far beyond the trivial 'let the manager learn science' or 'let the scientist learned how to sell'" (p. 83). The profound extension of either, or both, relationships based on unidirectional 'understanding' appears as the fourth type of relationship - that of 'mutual understanding'.

A phrase as benevolent as "mutual understanding" is likely to suggest a weak conclusion for a position that intends to assert something quite radical...The 
manager understands the scientist only by becoming something of a scientist himself, because he must purposefully respond to what the scientist qua scientist is trying to do. The scientist understands the manager only by becoming something of a manager himself, because he must purposefully respond to what the manager qua manager is trying to do. (p. 73).

Despite the reasonable expectation that in the rapidly evolving field of ISD a scheme that was developed over 40 years ago might have exceeded its 'use-by' date by now, this typology provides an apt instrument for progressing understanding of the problematic social nature of the problem of implementation. Thus far in this paper (e.g. Figs. 1 and 2), 'social' has referred to what is on the 'other' side of the technology of an IS that is used in farm decision-making or envisioned being used by those designing the intervention. The focus has been the 'internal' nature of farmer/managers as personal agents, information seekers and technicians and the contrasts with scientists'/DSS builders' assumptions about them. The 4-cell 'understanding' typology of Churchman and Schainblatt escalates the 'social' from matters of individual behaviour to include relationships between the scientist/interventionist and the farmer/manager. Although the paper created quite a 'stir' at the time (indicated by Churchman and Schainblatt, 1965b), it can now be seen as a significant nudge to no less than a paradigm shift in systems thinking and practice regarding IS implementation.

Having introduced these four types of social relationships between scientist and manager in implementing a DSS, these will now be examined more closely in the context of the agricultural DSS.

\subsection{Minimal relationship between scientist and farmer-reliance on clever design and mass distribution.}

The majority of serious efforts to improve adoption of DSSs have paid attention to (1) making models realistic representations of farming, (2) making software easy to use, and (3) making the system more accessible, e.g. through commercial software distributors (Donnelly et al., 2002) or on the Internet (Welch et al., 2002). All three qualify for Churchman and Schainblatt's 'separate-function' relationship between the scientist/modeller and the farm manager. In this relationship, when a system builder is made aware of practitioner indifference for their product the normal response is to improve the technology. One common strategy has been to make the model more relevant by making it a more realistic representation of the farm system. This is typified by the following diagnosis by two Australian decision analysts:

... analysts must come down to earth and confront the realities of actual farms and farmers. It will be necessary to take account of the resource endowments of individual farmers, of the alternative uses of these resources, and of their preferences and perhaps also beliefs. In other words, whole farm decision modelling may have to be attempted (Anderson and Hardaker, 1979, pp. 19, 20; my emphasis). 
Using the same strategy, Dent (1990) recommended radical redesign of the decision calculus type of DSS (McCown, 2002, this issue, Fig. 3).

The problem for individual farmers becomes one of designing the scale and structure of enterprise systems in such a way as to operate within the resources and cultural constraints of the household and to meet multifaceted objectives. [...] For those interested in studying such whole-farm systems by way of models, social, cultural and economic sub-systems must be added to the biological components of crop or livestock models in order to prescribe integrated enterprise strategies that provide more successfully for the well-being of the farm household (Dent, 1990, p. 120).

This presumption of inadequacy due to insufficient model comprehensiveness was introduced earlier in discussion of design criterion of CALEX/Cotton, as recounted by Plant (1997). The builders aimed to "develop an integrated program that would provide comprehensive support for crop management decisions.

CALEX/Cotton, like other contemporary crop production decision support programmes, was as comprehensive as we could make it. The motivation for this approach was to use the computer's power and speed of calculation to integrate all facets of crop production (p. 37).

But non-use by farmers of the comprehensive model led this team to conclude that "comprehensiveness does not necessarily equal quality," and the integrated, comprehensive CALEX/Cotton was replaced with "much smaller and more specialized programs" that deal with the very practical task of intensive description of dynamic crop yield potentials (Plant, 1997, p. 35).

The integrated decision support system (IDSS) became fashionable for a period (e.g. Plant and Stone, 1991). Wagner and Kuhlmann (1991) open their paper on the IDSS with the technical observation that "During the evolutionary process of developing software for management tasks, the need for integration became more and more obvious." But in the end, they reached the contrary practical conclusion that

The interdependences between so many programs as in the above-described IDSS are of a very complex nature. Thus, the 'black box' simply becomes too big for the user to accept without any doubts. Therefore, many users prefer stand-alone programs (Wagner and Kuhlmann, 1991, p. 309).

This history of regression from the complex-that-failed to the simpler is a reminder of the essential practicality of the principle of evolution embodied in the systems aphorism "any complex system that works began as a simple system that worked." This seems to be central to the stance taken by Hearn and Bange (2002) in the 'bottom up' vs. 'top down' debate regarding models in decision support.

Ironically, the 'separate function' relationship was implicit in the original concept of the DSS. Personal use of the software was intended to fix the problem of intervention 
too high in the manager's action tree by a scientist-intermediary with a model (Little, 1970). But as it turns out, the fix has had its own 'problem of implementation'. The DSS in this normal, separate-function mode fails to recognise the importance to this socio-technology of a 'participatory' mode. The remaining three relationships between modellers and farmers all entail some mode of 'participation,' but the mode varies in important ways.

\subsection{Communication with/education of farmers}

One of the most obvious strategies for improving implementation is to provide opportunities and support for farmers to learn about the merits of the DSS for their management as well as to gain a scientific understanding of the management issues concerned. The desirability of the latter benefit is not a question for most farmers, but the feasibility of having the required time and attention almost always is. Farmers often take advantage of educational opportunities offered by DSS marketers. Farmer attendance at workshops and courses have been integral to implementation of CottonLOGIC (Hearn and Bange, 2002), CALEX-Cotton, (Goodell et al., 1993), and NUTBAL (Stuth et al., 2002).

When the degree of training that is required obviously exceeds the resources a farmer can commit, there is a case for training of a professional service provider as long as the demand for a service by farmers is sufficient to justify the investment. Intensive training for providers of advisory services to farmers has been integral to GLA and NUTBAL, GrassGro, and FARMSCAPE. This placement of an intermediary between the farmer and the scientist might seem to more a case of the 'selling' strategy (later). But as Carberry et al. (2002) point out, researcher facilitation of farmer learning about new possibilities and new ways of seeing aspects of their production system was instrumental in the development of a latent market 'pull' that provides initial incentives for investment by service providers in their development of new skills to serve it.

\subsection{Persuasion of farmers to adopt a DSS}

The boundaries between the categories of communication/education and persuasion/selling are not rigid. A training course constructed around a DSS is not likely to be devoid of implicit, if not explicit, persuasion. When understanding the theory and perceiving its relevance and significance for practice is infeasible, the next best thing may be becoming convinced of its value. The decision analysts, Anderson and Hardaker, perceived an important 'selling' relationship.

...the practical value of the theory in decision analysis depends upon the feasibility of convincing real-world managers of the merits of a systematic approach to their decision problems and on their assessments of the relative costs and benefits of systematic vs. intuitive decision making (Anderson and Hardaker, 1972, p. 181). 
Farmers can be expected to judge a DSS on its costs and benefits. But any such evaluation is problematic because of multiple uncertainties. As discussed earlier, the DSS notionally qualifies as "a technology...for instrumental action that reduces the uncertainty in the cause-effect relationships involved in achieving a desired outcome' (Rogers, 1995, p.35). But, this is a technology that, if adopted by a farmer, will change his/her management process and inevitably bring a new class of uncertainty.

But a technological innovation also creates another kind of uncertainty because of its newness to the individual and motivates him or her to seek information by means of which the new idea can be evaluated. This innovation-evaluation information leads to a reduction in uncertainty about an innovation's expected consequences (Rogers, 1995, p. 35, 36).

Rogers' first type of uncertainty is technical; his second is practical. It is the practical uncertainty of an innovation that constrains its implementation, and reduction of this uncertainty is the key to successful 'selling'. Remarkably, high tech marketing experts in Silicon Valley have appropriated, revived, and refurbished the model of technology diffusion that developed about 60 years ago in agricultural extension.

The revamped model has been popularised in a best selling management book by Geoffrey Moore (1991) entitled Crossing the Chasm. The so-call 'chasm' is a hitherto unrecognised feature of the well-known 'bell curve' of rates of adoption, which originated in pioneering work concerning the adoption of the innovation of hybrid corn (Ryan and Gross, 1943) and evolved as a means of categorizing 'adopters' of new technology in agriculture and many other domains (Rogers, 1995). (Silicon Valley-based Moore makes the minor mistake of attributing origins to 'adoption of new strains of seed potatoes'.) The best-known features of this model are categories of adopters based on relative earliness of their adopting: Innovators, Early Adopters, Early Majority, Late Majority and Laggards. In the conventional agricultural model, effort in persuading/selling is aided by interactions between target groups by the process of diffusion.

Marketing professionals insist on market segmentation because they know that no meaningful marketing program can be implemented across a set of customers who do not reference each other. The reason for this is simply leverage. No company can afford to pay for every marketing contact made. Every program must rely on some ongoing chain-reaction effects - what is usually called word of mouth. The more self-referencing the market and the more tightly bounded its communications channels, the greater the opportunity for such effects (Moore, 1999, p. 29, 30).

There has been a presumption that the successful adoption experience of a market category provides innovation-evaluation information that reduces the next group's uncertainty about costs and benefits in their situation. Moore's insight is that the experience of the Innovators and Early Adopters, who he lumps as visionaries, does 
not in fact serve to reduce uncertainties for the pragmatists who comprise the Early Majority, because the experience of the visionaries is not seen by the pragmatists as relevant to them.

By being the first to implement this change in their industry, the early adopters [the visionaries] expect to get a jump on the competition...By contrast, the early majority [the pragmatists] want to buy a productivity improvement for existing operations. They are looking to minimize the discontinuity with the old ways. They want evolution, not revolution. They want technology to enhance, not overthrow, the established ways of doing business. And above all, they do not want to debug somebody else's product.

Because of these incompatibilities, early adopters do not make good references for the early majority. And because of the early majority's concern not to disrupt their organization, good references are critical to their buying decisions. So what we have here is a catch 22 . The only suitable reference for early majority customer, it turns out, is another member of the early majority, but no upstanding member of the early majority will buy without having first consulted several suitable references (p. 20; My emphasis and interjections).

It is never the case that no farmers ever use a DSS produced to aid their management. But application of the 'chasm' theory, suggests that users are 'visionary' farmers, and the DSS fails to 'cross the chasm' to be used by the 'pragmatists.' By not crossing, an effort fails to achieve the critical market size that would retain funding and/or agency political support. This is the significance of the 'chasm': only about $15 \%$ of potential customers are comprised of visionaries on the left side of the 'chasm'- the left 'tail' of the bell curve.

\subsection{Mutual understanding between DSS scientists and farmers}

Churchman and Schainblatt's first three relationships represent alternative ways to get the manager to come to accept the science-based DSS product on offer as a means of improving management practice in ways anticipated in the DSS design (Fig. 1b). These are all forms of normative intervention in farming practice. It is the 'practice guiding' goal of policy research (Oquist, 1978; McCown, 2002, Fig. 2), based the superiority of the scientific understanding and representation of the farm management reality for designing what a rational farmer ought to do in this type of situation.

The 'mutual understanding' relationship between farmer and scientist differs from the first three in two major ways. First, it accepts the existence of multiple legitimate views of 'reality' with regard to the human activity of farming. In contrast to seeing the main task of intervention as gaining acceptance of the science-based, external representation of reality as a guide to action, the first step in an intervention based on mutual understanding is the gaining of understanding of the farmer's internal management practice. Importantly, this takes place not by interpreting farmers' 
behaviour, but by finding out what the farmer thinks (s)he is doing in this behaviour and his/her reasons for doing it (Flood and Ulrich, 1991, p. 194). Second, the very notion of 'intervention' is negotiated as a possibility with potential mutual benefits, the nature and degree of which may be ill-defined at the outset. The main aim of the intervention is to discover/invent benefits in the interaction. The effect of a farmer's uncertainty about benefits on his/her motivation for participating tends to be compensated for by the obvious high degree of relevance to practice ensured by this social process.

In social science, a common way of talking about the first three of Churchman and Schainblatt's modes for intervention by a scientist in farm management practice is that they typify the 'functionalist' paradigm of intervention in practice (Burrell and Morgan, 1979). Emphasis is on the quality of the knowledge of scientists on the 'outside' of the farming practice and its value in optimising functionality of means to achieve farmer goals, an approach made possible by the singularity of objective reality. By contrast, the mutual understanding mode typifies the 'interpretive' paradigm (Burrell and Morgan, 1979), alternatively known as 'social relativism' (Hirschheim et al., 1995).

In the context of the interpretive paradigm the central endeavour is to understand the subjective world of human experience. To retain the integrity of the phenomena under investigation, an attempt is made to get inside to understand from within. The imposition of external form and structure is resisted, since this reflects the viewpoint of the observer as opposed to that of the actor directly involved. (Burrell and Morgan, 1979, p. 253).

This 'new' paradigm became the basis for reform in a time of IS implementation crisis in the main systems movement (e.g. Rosenhead, 1989; McCown, 2002). It is the philosophical foundation for soft systems thinking (Checkland, 1981) and for the research and intervention methodologies of action research/participatory action research (Fig. 3). Something of the paradigm change in the OR/MS movement is captured in the preface of the 1989 proceedings of a symposium in descriptions of change since a symposium held 25 years earlier.

Few, these days, regard OR as being simply applied mathematics. The recognition that $\mathrm{OR}$ is a process of intervention in organizational and human affairs is now wider and more explicit. There has been a penetration and diffusion of ideas from the social sciences into OR, reflected most strongly in the body of writing about soft OR methods and soft systems thinking. Social and political skills are now recognised as critical to the success of OR practice, and this is particularly so as operational researchers have sought to extend their client base outside that conventionally served. The rise of computer technology, embraced by OR, has required some thought to be given to its powerful impact on and consequences for organisations, people, and processes of decision. As a consequence, perhaps, of broadening its methodological base in attempting to extend its impact, OR has encountered the problem of competing 


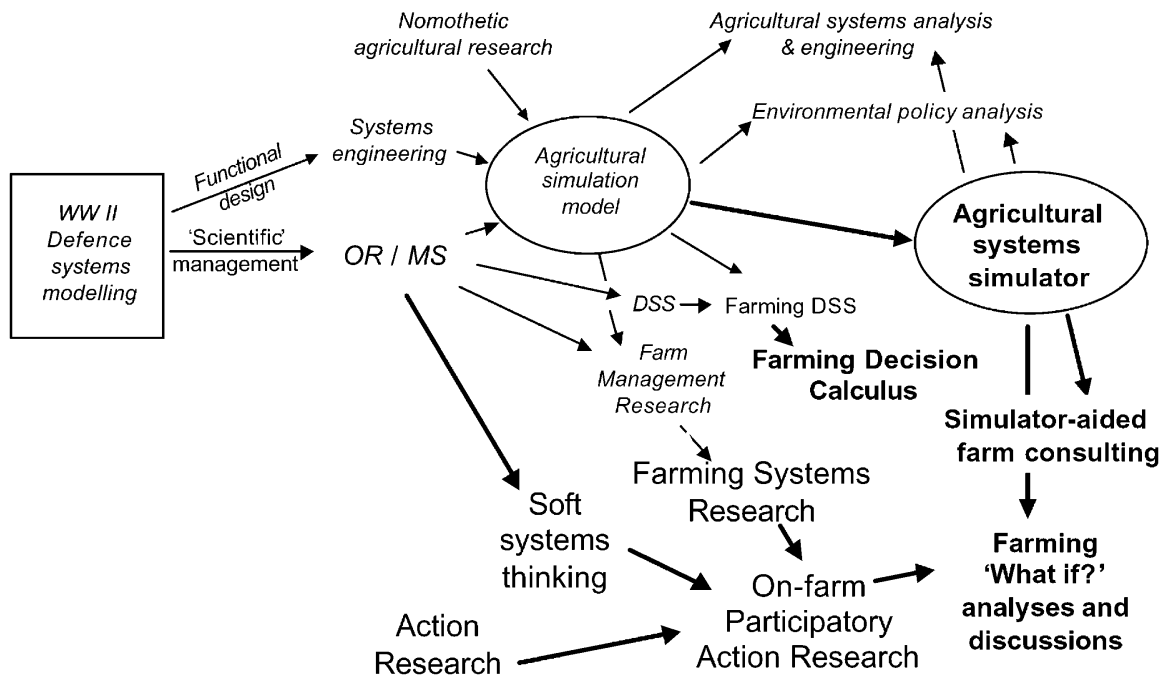

Fig. 3. Extension of the 'family tree' of the agricultural DSS in McCown (2002) showing the new influences of an 'interpretive' intervention paradigm and the versatile systems simulator.

'paradigms' - a condition long experienced by the social sciences (Jackson et al., 1989, p. v).

The grounds for competition between paradigms stem from the distinction between Policy Research and Action Research (Oquist, 1978; McCown, 2002, Fig. 2). Both are concerned with "the production of knowledge that guides practice." As a natural extension of descriptive and nomothetic forms of natural science research, policy research uses scientific/economic knowledge and models to design best action for the practice situation from the 'outside' - the classical 'hard' systems approach of OR/MS (Fig. 1b). Action research, on the other hand, features experiential knowledge gained in the practice situation. As professional research, it entails 'outsiders' joining practitioners in processes of Fig. 1a in order to gain first-hand 'insider' understanding. Action research guides practice by enhancing grounds for managers' judgement-making by facilitating learning from new, salient experiences. This is often further enhanced by insights to substantive system structure. Action research simultaneously provides insightful experiences for participating scientist outsiders that benefit their own future practice. A notable historical example is the action research program by which Soft Systems Methodology evolved Checkland (1981, p. 146). A very recent example in agriculture is the evolution of the FARMSCAPE approach (Carberry et al., 2002; Hochman et al., 2000).

The role of the outsider to developing information systems (ISD) in this interpretive paradigm (social relativism) is elaborated by Hirshheim et al. (1995).

The basic metaphor for the process of systems development [ISD] in social relativism is to build systems which facilitate sense making and mutual under- 
standing. The role of the analyst is that of a facilitator for social evolution and change. [...] It recognizes that knowledge about human means and ends is not easily obtained because reality is exceedingly complex and elusive. There is no single reality, only different perceptions about it. [...] goals are ambiguous, multi-functional and conflicting. System objectives emerge as part of the organizational construction of reality, the 'sense-making process.' The role of a system developer is to interact with management to find out what type of system makes sense; but there is no objective criterion which distinguishes good from bad systems. It all depends on what the parties come to believe to be true. The developer should work from within the users' perspective and help them to find their preferred views. He should ease the transition from one viewpoint to another, thereby alleviating possible resistance to change. Ideally the developer-by virtue of prior experiences, wisdom or special insights - is able to reduce the pains of change.

Hence social relativism emphasizes problem uncertainty and the process of negotiation and clarification to reduce it. Overall, the purpose and direction of change is hidden from all participants, and the analyst's expertise is similar to that of the midwife who can ease the process of birth and make sure that the baby emerges safe and sound, but has no part in 'designing' its genetic characteristics (Hirschheim et al., 1995, pp. 73, 74).

During the 25 years between the two OR conferences (previous quote from Jackson et al., 1989), the 'problem of competing paradigms' was intense, and much attention was given to philosophical critique of the functionalist paradigm and its underlying philosophy of science. Significantly, during the 1990s, a remarkable attitude shift in the systems field took place in which the practical value rather than the philosophical correctness was suddenly of primary importance. Complementarity and utility in multi-methodological intervention pushed philosophical critique, not out, but into the background (Ormorod, 1995; Mingers and Gill, 1997). In the same way that developments in mainstream management science, such as the DSS, have historically influenced agricultural systems research, this development paves a promising way for researchers in agriculture who are contemplating a future for models in aiding farming practice.

As indicated by Hearn and Bange (2002, this issue, p. 36), interaction between farmers and DSS workers based on 'mutual understanding' is not a new phenomenon. But when it has occurred it has been an adaptive, or even incidental, aspect of professional practice. The case of FARMSCAPE, which can be viewed as an instance of 'new' paradigm research in this eclectic, multi-methodological sense, initiated this approach naively (Carberry et al., 2002, this issue). Recognizing the problem of DSS implementation but believing that simulation of cropping systems should be useful to farmers, the research aim here was to establish the conditions in which a farmer would choose to access this technology. Could a farmer, exceedingly sceptical about 'models,' come to value simulation of crop production systems in management when operational obstacles were minimised, local credibility maximised, and the simulator made as versatile as possible? This qualifies as the DSS 
work that Stabell (1987) termed 'Implementation Process' research (McCown, 2002, Fig. 3). In establishing mutual understanding, the researchers operated in an interpretive paradigm. Soft system characteristics include engaging farmers on their felt problems, targeting of their uncertainties, and providing benefits more like novel experience than recommendations. But the core resource for social engagement was a flexible simulator, a product of nomothetic research and software engineering in the hard systems paradigm and normally used in intervention within the functionalist paradigm of OR/MS. Combining the heritages of OR/MS, farming systems research, and participatory action research into a multi-methodological and multiparadigmatic intervention activity, this appears in Fig. 3 as "Farming 'What if?' analyses and discussions".

\section{Future prospects for model-based intervention in farming practice}

There is every reason to expect that farmers' dependency on computers will continue to grow, in keeping with trends in the wider society. But there is little reason to believe it will eventually be evident that the agricultural DSS 'crisis' has resulted because the DSS for farmers was "an idea ahead of its time". Not only has the DSS (in and outside agriculture) not been a conspicuous empirical success, but the underlying philosophical and theoretical concepts that rationalised the original DSS notion have also been superseded, and their successors point in new directions. One of the original 'cornerstones' of the conceptual foundation of the DSS was 'bounded rationality.' His contribution of this concept to the science of economic decisionmaking won Herbert Simon a Nobel Prize in 1978. Simon's point was that the problem in human practice is not so much that human decision-makers are not rational, but that the knowledge about the world that might enable ideal action is often inaccessible. Yet, as the epigram of this paper reminds us, we must take decisions in spite of uncertainty, and part of fallible human practice involves the sorting out of unexpected and unwanted consequences of assumptions. An irony for the field of decision support is that the concept of bounded rationality was originally taken as the conceptual foundation for building rationalistic tools for decision makers in cognitive need (Keen, 1987; Stabell, 1987). Yet after the experiences of the low use of their products and after the 'situated cognition' revolution, it is the builders of decision support systems who are seriously 'teasing out the consequences of their assumptions'-experiencing the consequences of their bounded rationality. This is an important aim of this Special Issue.

My focus in (McCown, 2002, this issue) and this final paper has been on the assumptions about the social in this socio-technology designed by technical experts. The most fundamental assumption has been that because decision-makers with bounded rationality are unable to consistently choose optimal actions, provision of formal analysis that identifies such an action would be a genuine contribution to better management. An accompanying assumption has been that rational managers would embrace this 'support'. Although learning that both these assumptions are almost always inadequate has been a major outcome of the agricultural DSS 
experience, it would be easy to oversimplify this finding. Certainly the concept of bounded rationality has not been invalidated as a constraint to farm management. Rather, the concept has been found to be more limited as an explanation for management behaviour than we have assumed (Winograd and Flores, 1986, p. 145), and formal analysis of the 'logic of the situation' is more limited as the key to improved management behaviour than we have assumed. It is now clear that farmers often cease to need computerised decision aids once a decision becomes routine. In addition, options for external guidance of farmer actions using information systems have increased to include not only intervention to aid better choice of actions but also intervention to facilitate learning and modification of decision process. With this new background, from the case histories, four paths for model-based information system development (ISD) aimed at benefiting cognitive aspects of farmers' management can be abstracted which differ in function and structure. The function in three of these is the reduction of decision uncertainties, but these differ in the particular uncertainties that they address. The fourth ISD path concerns the function of aiding the conforming to external requirements for farm management action by enhanced justification and/or documentation. Structural differences cut across these functions: the important distinction is whether the benefits of the IS are provided via an expert intermediary or a via DSS run by the farmer. In the main, these 'paths' can be seen as niches that remain promising in what was seen 25 years ago as a broad landscape of possibilities. Although these four ISDs are discussed below as ideal types', they are obviously not mutually exclusive, and are often found in combinations.

\subsection{Use of a DSS as a tool in farm decision-making for highly structured tasks}

The first path is production of the DS tool that aids deliberation of what action to take. Its contribution is in reducing uncertainty about expected consequences of alternative actions, given existing conditions, and it does this in either (or both) of two ways. It may have a 'logic' that is powerful in calculating or inferencing outcomes from actions and given conditions or it may innovatively provide new 'existing conditions' by derivation of a diagnostic system parameter that has been previously inaccessible, under-utilised, and/or relatively costly (denoted in Fig. 3 as 'Farming decision calculus').

An example of a powerful logic or calculus is SIRATAC's capability to relate early crop insect infestation and damage to final yield in a way that took into account the crop's ability to compensate for the damage. Another is calculation by WHEATMAN of the optimal trade off of risks of frost damage to wheat crops flowering early against that of truncated grain fill by terminal soil drying of late-flowering crops.

Examples of novel exploitation of unconventional system state information include insect counts in SIRATAC, EPIPRE, and CottonPro, the plant map of CottonLOGIC, CottonPro, and GOSSYM/COMAX, estimation of nutritional value of pastures from low cost faecal analysis (NUTBAL) or unconventional pasture description (GrazFeed), enhanced use of localised weather data provision (PCYield), enhanced interpretation of abstract seasonal weather forecast instruments, e.g. the Southern Oscillation Index (e.g. Nelson et al., in press), and deep soil $\mathrm{N}$ of 
FARMSCAPE. Such information on system state may be valuable in its own right to managers with the appropriate experience and/or training. A number of products combine the strategies of novel information and powerful logics or calculi, as indicated by entries in both 'DSS Functions' 1 and 3 or 4 of Table 1.

Such tools are located in low, technical branches of the action tree (Fig. 2) and hence tend to be comfortably delegated to machines, consultants, or both. A significant challenge is achieving sufficient penetration of the market to provide the sound commercial footing that will be especially important as public funding for DSS research declines.

\subsection{Use of a versatile simulator in farm consulting}

A second path for ISD in farming is the use of a general-purpose simulator by an intermediary for servicing management needs, denoted in Fig. 3 as 'Simulator-aided farm consulting.' The uncertainties addressed here are both tactical and strategic. Tactically, versatile simulators offer the opportunity to explore consequences of a wide range of possible actions beyond the farmer's experience; strategic use includes evaluation of consequences of possible changes in enterprise structure. Among the cases in Table 1, GLA and GrassGro were designed to support strategic planning in grazing systems. These inevitably concern strategic calculation of the horizon of safe limits to grazing exploitation for a specific location and more tactical deliberation and decisions concerning change to current grazing pressures (see specific case studies in Donnelly et al., 2002). Explorations with farmers of climatic risks to contemplated changes to cropping enterprises are an important aspect of FARMSCAPE (Carberry et al., 2002).

Among the cases, APSIM in FARMSCAPE and GrassGro qualify as system simulators rather than DSSs. Superficially, intermediaries using versatile simulators may look like simply a return, as a result of disappointment with DSS implementation, to the pre-DSS days of OR/MS when a systems analyst provided a service to a manager. But there have been significant developments in both technological and sociological aspects of IS that enable such a change to be profoundly different to the earlier form.

Technically, there have been enormous advances in simulation capabilities attributable to both hardware and software advances. The versatile 'simulator' (e.g. Banks et al., 1991; Keating et al., in press; Freer et al., 1997) is not the same as the complex mechanistic models criticised by Hearn and Bange (2002) as inefficient instruments for driving a DSS. The key difference is that in contrast to the mechanistic model, the primary aim in making a simulator is not to mimic system process but rather system function and performance, and to do so cost-effectively. Flexibility and ease of specification are key simulator attributes. The simulator, by being flexible, pragmatic in information requirements, and having no inbuilt objectives provides the ideal IS for conducting 'what if?' analysis with farmers (e.g. Carberry et al., 2002), a feature missing in models that mathematically optimise.

The recognition that interactivity of managers and computers - the structural feature that most characterised the break of DSS with OR/MS - was not essential occurred within the first decade of the DSS era. In response to criticism of the DSS 
based on the reluctance of senior managers to use them, Watson and Hill (1983) pointed out that very early in the DSS era, this reluctance was recognized and rationalized.

Keen (1975) argued that instead of trying to bring unwilling managers to the computer with user-friendly software interfaces, we should focus on the accessibility of decision support system applications by...the use of...skilled intermediaries. [...] managers who lack modeling expertise or who do not know the assumptions and details underlying the DSS [should] be discouraged from direct use of the system. What is important is not that the decision support system is interactive, but that it is responsive. The key issue was not whether the user or manager could talk to a computer to get the answers he needed, but rather, whether a combination of people, data, models and technical tools could provide these answers in a convenient, timely, and cost-effective manner (Watson and Hill, 1983, pp. 85, 86; my emphasis).

The structural, and ultimately, social/behavioural problem which the DSS was meant to avoid was caused by expert analysts-with-models planning for managers, designing what external theory indicated they ought to do, and running into conflict with the internal policy and judgement of managers-performance of which presumably served to get the manager in a position of high discretion and agency in the first place. It was anticipated that the DSS innovation would deal with structured (technical) problems 'delegated' by the manager, leaving ill-structured (practical) ones for managerial expert judgment. For the reasons summarised in Fig. 2, this notion has proved to be too simplistic. But if return to the practice of intermediaries managing the models is going 'full-circle' to mimic the early OR/MS normative educational or persuasive processes in order to gain farmer compliance with the interventionist's ends and/or means, and ignoring the need for mutual understanding, this would indicate a failure of organizational learning and confirmation of a crisis destined to be terminal.

Quite apart from any theoretical considerations, a key pragmatic test of whether the social causes of the problem of implementation have been avoided or overcome is sustained commercial success in providing computer-based farming decision support. It seems safe to predict that any arrangement by which models are used by intermediaries as the basis of a service to farm managers will persist only if there is a genuine market for the service and sufficient 'willingness to pay' to provide adequate financial returns for suppliers. To my knowledge, commercial viability of a system for decision support provided by a consultant using a complex simulator has yet to be demonstrated, but 'experiments' are in progress (Donnelly et al., 2002; Carberry et al., 2002). Only time will tell if the necessary profitability conditions for success can be met.

\subsection{Use of a versatile simulator in facilitation of farmer learning and development}

This third development path, denoted in Fig. 3 as 'Farming 'What if?' analyses and discussion" is characterised by intervention with externally-facilitated manager 
learning rather than external design of management practice (Checkland, 1991). In the program of developing an information system for farmers that is useful and used, this represents a shift from intervention with a premium on the quality of the technology and the underlying science to intervention with a premium on achieving mutual understanding with farmers as a first step in using models in co-creating new value in reducing management uncertainties.

As this paradigm emphasizes the complexity of systems development, it doubts the efficacy of objective and rigorous methods and tools. Instead, it favors an approach to systems development that facilitates the learning of all who are concerned and affected. This implies a switch in role of the developer from one of system expert to facilitator who helps to stimulate reflection, cooperation and experiential learning. In practice the social relativist [interpretive] approach seeks to provide specific tools that the facilitator at his discretion may use to support the project group interaction (Hirschheim et al., 1995, p. 76, my interjection).

This path addresses, first and foremost, uncertainty about the computer-based decision aiding technology, including testing its credibility, practicality to specify for the situation, and its usefulness in thinking about management problems and opportunities. Initial interactions provide the innovation-evaluation experience of Rogers (1995, p. 36).

As Carberry et al. (2002) report, a versatile simulator can be an effective tool for a facilitator to use in interactions on management, but it becomes so only after farmers, initially sceptical about models of a farm system, satisfy themselves of the simulator's ability to adequately mimic important aspects of their production situation and system function. In this paradigm of intervention/implementation, the rigour of the models and conduct of simulations becomes secondary, in the sense that even hypothetically perfect technology will not be effective without construction of relevance for the farmer's practice. But even when simulation is secondary, its quality is crucial. Failure to pass farmers' demanding tests of credibility is no less fatal in this ISD path than in Path 1, above.

This primary intervention paradigm of this path is one of social relativityunderstanding of and recognition of the value and legitimacy of a situated practical worldview (the interpretive paradigm). The biophysical models of the production system are products of a 'universal' scientific worldview. But there is a convergence when it comes to realities of the natural world that are relevant to situated practice. The farmer and the scientist are both philosophical 'realists' in matters of acting to alter the biophysical world. Farmers generally need help to see if/how a model can be relevant to their practice. But if, in the interaction, a potential relevance is appreciated by farmers, they apply demanding standards on model performance (Carberry et al., 2002; Hochman et al., 2000). Actual relevance to a farmer depends in part on demonstration of the model's credibility against his known 'real world facts.'

The experience over 10 years in dryland cropping regions of Australia is that when relevance is appreciated and credibility established by a farmer, a versatile simulator 
often becomes for him/her a valued opportunity to conduct meaningful 'what if?' management experiments, facilitated by a skilled intermediary. But this instance of scientists taking an interpretive ISD path can be seen as an experience in rediscovery of what others before them had found outside of agriculture. Although OR/MS developed a reputation for normative 'designing' of clients' practices, Naylor (1982) reminded readers that there had been another mode of decision support.

While some [OR/MS] methods are normative in nature and have as their objective prescriptions of proper managerial behavior, others, such as corporate simulation models, simply enable managers to evaluate the consequences of different strategic options. Corporate simulation models were used by executives to deal with ill-structured problems long before DSS came into vogue (Naylor, 1982, p. 93).

This 'minority' tradition survived in the corporate world and has recently reappeared as the 'learning laboratory' and the 'management flight simulator.'

The goal of a learning laboratory is to provide an environment that will help enrich managers' mental models using tools such as the management simulators. Learning laboratories help managers leverage their domain-rich knowledge by allowing them to play through simulated years, reflect on their actions, modify their mental models, then repeat the process. By compressing time and space, flight simulators can accelerate learning by enabling them to conduct many cycles of action and reflection (Bakken et al., 1994, p. 246).

If we view learning as a process where an action $\rightarrow$ result $\rightarrow$ reflection $\rightarrow$ learning leads back to further action, flight simulators can facilitate learning by shortening the delay between action $\rightarrow$ results. The simulator also demands structural explanations of the action $\rightarrow$ result link that will force participants to search for a better understanding of the underlying forces that produce a given set of outcomes. The design of the learning laboratory also increases reflection and enhances learning out of which better decisions can arise. (Bakken et al., 1994, p. 250)

In agricultural ISD, this is new and unfamiliar territory. But it appears to be a promising path for making models meaningful to farmers' management to a degree that has rarely been seen with decision support systems. But as exciting as learning how to bridge the gap between modellers and farmers is, this ISD path is primarily a research domain. But it is 'research with a difference.' It is research with a degree of involvement in practice that qualifies it as what Gibbons et al. (1994) have termed Mode 2 research.

...it is increasingly the case in computer, materials, biomedical, and environmental sciences that theories are developed in the context of applications and

\footnotetext{
${ }^{5}$ The action learning cycle in Action Research (Reason and Bradbury, 2001).
} 
that these continue to fertilise lines of intellectual advance that lie outside disciplinary frameworks. In Mode 2 things are done differently and when things are done differently one is entitled to say a new form has emerged (Gibbons et al., 1994, p. 9, 10).

\subsection{Use of a DSS in meeting external regulatory demands}

A fourth path is the production of tools that help farmers in the 'control' function of management primarily to meet external requirements for management. External influence can take two forms, both illustrated by Hearn and Bange (2002). They report that support for SIRATAC was strongest among the large corporate farms because it provided an instrument for standardising management among multiple farms and managers. In the action tree of such structures, senior managers delegate production decisions to farm managers whose behaviour is regulated by rules and other formalisms in the software. In the more 'industrialised' agricultural industries (intensive pig, dairy, irrigated high value crops, etc.), use of such DSSs in corporate organizations may become important in the future.

The second form of external influence is pressure from the community at large that farming be conducted within norms and standards for environmental conservation and safety. Adversarial pressure from individuals and interest groups is felt by farmers via public media, potential for litigation, and potential for more stringent legislated regulations. The Australian cotton industry has endorsed Best Management Practice and is undertaking to adopt it and audit its use as evidence of selfregulation. A DSS like CottonLOGIC, which not only provides guides to action that conform to industry 'best practice' standards but provides a convenient instrument for keeping records of events and actions, seem to be a useful instrument for formalising self-regulatory efforts. Hearn and Bange (2002) report that 50\% of consultants use CottonLOGIC, and $31 \%$ of all decision makers in the industry. But it is not clear to what degree the 'use' stems from a 'protection' rationale or from the more usual 'production' rationale. This seems important not only to efficient design of a DSS but to meaningful interpretation of comparative statistics on ownership and use.

Although CottonLOGIC supports decisions on irrigation, fertilisation, and pesticide application, there are logical reasons why the need for and use of this functionality might be low. In such capital intensive cropping systems cotton crops will rarely be put at risk of resource shortages. The main uncertainty/risk is not undersupply of production inputs, but oversupply of inputs that might be ecologically undesirable. In contemporary circumstances, for both farmers and consultants, motivation to save costs can be expected to come second to protection against culpability for perceived environmental damage.

Products such as GLA (Stuth et al., 2002, this issue) in the hands of public environmental protection agencies have the potential for regulatory intervention on a scientifically rational basis. The nature of these pressures and the corresponding nature of the IS tools place these high enough in the action tree to be resented as proxies for managers' freedom to decide and act. But under circumstances of changing public 
attitudes concerning land use and management, adaptive political behaviour may require relinquishing a degree of discretion and agency, and such erosion of freedom of choice and action is nothing new to farmers in recent times (Mooney, 1988).

\section{Conclusions about learning from the DSS experience}

For many agricultural professionals with experience in building and implementing DSSs, the activity has been peripheral to the main enterprise of modelling. There is no doubting the good intentions of researchers to provide tools that would benefit farm management. But, when expectations of farmer adoption and use have not been realised, a common response has been to turn to other activities in the research portfolio rather than try to learn from the disappointment, make appropriate adjustments, and try again ${ }^{4}$. There has been a tendency to quietly accept the market failure as tolerable in the context of other research successes. The aim of this Special Issue has been to challenge authors to focus on such understanding by reflecting on their experiences. But in one case, the constraint of this focus ultimately proved to be unacceptable to the authors, one of whom, in response to an editorial intervention, wrote:

You relegated many of our [model development and non-DSS application] achievements to tables pointing to the references. None of the readers we are addressing will look up those references. So, what you have done is delete the heart of our story leaving an incomplete record of failure as abject as that of [others]. You see, although our attempt at DSS was well known we were never solely or exclusively committed to it. [The Agency] was always apprehensive about it and we generated all of our support (hard and soft money) with other applications. We were able to do this because we were building a general purpose simulation model based in hard science

As long as a DSS is afforded such a low priority (and I don't think this is an exceptional case), it will be rational at this level to avoid the challenge of the 'problem of implementation,' rather than to struggle to alleviate it. But at another level, this is a most inadequate state of affairs. At this level it is important to discover the actual potential of such tools in farm decision-making. This is important to farmers and their industry, but to other stakeholders in ecologically sustainable farming and the production of safe products as well.

In the main, the agricultural DSS experience has been a natural extension of a tradition sketched using the smaller font in the upper part of Fig. 3. But the experience in other fields indicates that adaptation for the future requires embracing an additional tradition sketched in the larger font in the lower part of Fig. 3. Nothing characterises this paradigm shift more than the shift in emphasis from 'design' to 'learning,' without abandoning design. Users must undergo an iterative learning and practice change process. The researchers must be prepared to be involved in, lend support to, and learn from this process - learn what the farmers are learning and 
learn what this means for conduct of their own future activity. This is the essence of action research.

Even when DSS implementation activities have been peripheral and learning has not been an explicit aim, reflective evaluation can contribute to learning from these experiences as long as the stories are told. But both the telling and the learning are often awkward for scientists and their organizations, for reasons eloquently set out by Feldman (1986).

The biggest motivational problem in learning from experience can be stated simply: "Everyone wants to learn, but nobody wants to be wrong." Learning from experience requires one to be wrong at least part of the time, but both public and private organizations tend to punish mistakes. [...] In short, in many organizations the evidence needed to learn from experience may be deliberately ignored (or hidden) because it would be damaging. . (Feldman, 1986, p. 283, 284).

We appear to be in transition from an era of, generally, uncritical exploitation of the DSS idea to one in which a combination of reflection and insight may enable delivery of more useful and more used computer-mediated scientific support for farm management. It is clear that a number of important experiments on changing systems for supporting farmers' decisions are in progress. The eventual impact may depend on Feldman's further admonition for change to facilitating learning from experience:

Reward people for the thoughtfulness of their analysis and the extent to which they properly evaluate their diagnoses and proposed solutions. This may seem to fly in the face of political reality, but no one really knows the degree to which [stakeholders] would respond to a sincere emphasis on experimentation and honest evaluation. Penalties should be imposed not for being wrong, but for refusing to learn. (Feldman, 1986, p.283, 284).

In today's uncertain agricultural R\&D climate, is the relevant question "Dare we heed this?" or is it "Dare we ignore it?"

\section{References}

Anderson, J.R., Hardaker, J.B., 1972. An appreciation of decision analysis in management. Review of Marketing and Agricultural Economics 40, 171-184.

Anderson, J.R., Hardaker, J.B., 1979. Economic analysis in design of new technologies for small farmers. In: Valdes, A., Scobie, G.M., Dillon, J.L. (Eds.), Economics and the Design of Small-farmer Technology. Iowa State University Press, Ames.

Anthony, R.N., 1965. Planning and Control Systems-A Framework for Analysis. Harvard University, Boston, MA.

Bakken, B., Gould, J., Kim, D., 1994. Experimentation in learning organizations: A management flight simulator approach. In: Morecroft, J.D.W., Sterman, J.D. (Eds.), Modeling for Learning Organizations. Productivity Press, Oregon, pp. 243-266. 
Banks, J., Aviles, E., McLaughlin, J.R., Yuan, R.C., 1991. The Simulator: new member of the simulation family. Interfaces $21,76-86$.

Berg, M., 1997. Rationalizing Medical Work: Decision-Support Techniques and Medical Practices. Cambridge, MA, MIT Press.

Boone, K., Porter, D.O., 1997. GOSSYM/COMAX - the quixotic quest. In: Proceedings of the Beltwide Cotton Conference, Memphis, TN, vol. 1, pp. 380-383. National Cotton Council of America, Memphis, TN.

Burrell, G., Morgan, G., 1979. Sociological Paradigms and Organizational Analysis. Heinemann, London.

Carberry, P.S., Hochman, Z., McCown, R.L., 2002. The FARMSCAPE approach to decision support: Farmers,' Advisers,' Researchers' Monitoring, Simulation, Communication, And Performance Evaluation. Agricultural Systems, this issue.

Checkland, P.B., 1978. The origins and nature of 'hard' systems thinking. Journal of Applied Systems Analyis 5, 99-110.

Checkland, P.B., 1981. Systems Thinking, Systems Practice. John Wiley, Chichester, UK.

Checkland, P.B., 1991. From optimising to learning. In: Flood, R.L., Jackson, M.C. (Eds.), Critical Systems Thinking: Directed Readings. John Wiley, Chichester, pp. 59-75.

Churchman, C.W., Schainblatt, A.H., 1965a. The researcher and the manager: a dialectic of implementation. Management Science 11, B69-B87.

Churchman, C.W., Schainblatt, A.H., 1965b. On mutual understanding. Management Science 12, B40-B42.

Clancey, W.J., 1997. Situated Cognition: On Human Knowledge and Computer Representations. Cambridge University Press, Cambridge.

Collins, H.M., 1990. Artificial Experts: Social Knowledge and Intelligent Machines. MIT Press, Cambridge, MA.

Collins, H.M., Kusch, M., 1998. The Shape of Actions: What Humans and Machines and Can Do. The MIT Press, Cambridge, MA.

Cox, P.G., 1996. Some issues in the design of agricultural decision support systems. Agricultural Systems 52, 355-381.

Davis, F.D., 1989. Perceived usefulness, perceived ease of use, and user acceptance of information technology. MIS Quarterly September 319-340.

Davis, F.D., 1993. User acceptance of information technology: systems characteristics, user perceptions and behavioral impacts. International Journal of Man-Machine Studies 38, 475-487.

Dent, J.B., 1990. Optimising the mixture of enterprises in a farming system. In: Jones, J.G.W., Street, P.R. (Eds.), Systems Theory Applied to Agriculture and the Food Chain. Elsevier Applied Science, London, pp. 113-130.

Donnelly, J.R., Freer, M., Moore, A.D., Simpson, R.J., Salmon, E., Dove, H., Bolger, T.P., 2002. Evolution of the GRAZPLAN decision support tools and adoption by the grazing industry in temperate Australia. Agricultural Systems, this issue.

Dreyfus, H.L., 1991. Being-in-the-World: A Commentary on Heidegger's Being and Time. MIT Press, Cambridge, MA.

Dreyfus, H.L., 1994. What Computers Still Can’t Do: A Critique of Artificial Reason. MIT Press, Cambridge, MA.

Feldman, J., 1986. On the difficulty of learning from experience. In: Sims, H.P., Gioia, D.A. (Eds.), The Thinking Organisation: Dynamics of Organisational Social Cognition. Jossey Bass, San Francisco, CA, pp. 263-292.

Flood, R.L., Ulrich, W., 1991. Testament to conversations on critical systems thinking between two systems practitioners. In: Flood, R.L., Jackson, M.C. (Eds.), Critical Systems Thinking: Directed Readings. John Wiley, Chichester, pp. 41-58.

Freer, M., Moore, A.D., Donnelly, J.R., 1997. GRAZPLAN: Decision support systems for Australian grazing enterprises. II. The animal biology model for feed intake, production and reproduction and the GrazFeed DSS. Agricultural Systems 54, 77-126.

Frost, F.M., 2000. Value orientations: impact and implications in the extension of complex farming syste ms. Australian Journal of Experimental Agriculture 40, 511-518. 
Gasson, R., 1973. Goals and values of farmers. Journal of Agricultural Economics 14, 521-538.

Gibbons, M., Limoges, C., Nowotny, H., Schwartzman, S., Scott, P., Trow, M., 1994. The New Production of Knowledge: The Dynamics of Science and Research in Contemporary Societies. Sage, London.

Goodell, P.B., Strand, J.F., Ostergard, M., 1993. Delivering expert systems to agriculture: experiences with CALEX/cotton. AI Applications 7, 14-20.

Habermas, J., 1971. Towards a Rational Society. Beacon Press, Boston, MA.

Hayman, P.T., Easdown, W.J., 2002. An ecology of a DSS: Reflections on managing wheat crops in the N.E. Australian grains region with WHEATMAN. Agricultural Systems, this issue.

Hearn, A.B., Bange, M.P., 2002. Computer-based decision support for the Australian cotton industry. Agricultural Systems, this issue.

Hirschheim, R., Klein, H.K., Lyytinen, K., 1995. Information Systems Development and Data Modeling: Conceptual Difficulties and Philosophical Foundations. Cambridge University Press, Cambridge.

Hochman, Z., Coutts, J.A., Carberry, P.S., McCown, R.L., 2000. The FARMSCAPE experience: Simulations aid participative learning in risky farming systems in Australia. In: Cerf, M., Gibbon, D., Hubert, B., Ison, R., Jiggins, J., Paine, M.S., Proost, J., Roling, N. (Eds.), 'Cow up a Tree': Learning and Knowing Processes for Change in Agriculture. Case Studies from Industrialised Countries. INRA Editions, Versailles Cedex, France, pp. 175-188.

Hodges, H.F., Whisler, F.D., Bridges, S.M., Reddy, K.R., 1998. Simulation in crop management: GOSSYM/COMAX. In: Peart, R.M., Curry, R.B., (Eds.), Agricultural Systems Modelling and Simulation. Marcel Dekker, New York, pp. 235-281.

Hofstede, G.J., 1992. Modesty in Modelling. Doctoral dissertion, Wageningen, Agricultural University, Department of Computer Science.

Howard, R.A., 1963. The practicality gap. Management Science 14, 503-507.

Humphreys, P.C., Berkeley, D., 1985. Handling uncertainty: levels of analysis of decision problems. In: Wright, G.N. (Ed.), Behavioral Decision Making. Plenum, New York.

Jackson, M.C., Keys, P., Cropper, S.A., 1989. Operational Research and the Social Sciences. Plenum Press, London.

Johnson, D.M., Erneling, C.E., 1997. The Future of the Cognitive Revolution. Oxford University Press, Oxford.

Jones, P., 1989. Agricultural applications of expert systems concepts. Agricultural Systems 31, 3-18.

Keating, B.A., Carberry, P.S., Hammer, G.L., Probert, M.E., Robertson, M.J., Holzworth, D., Huth, N.I., Hargreaves, J.N.G., Meinke, H., Hochman, Z., McLean, G., Verburg, K., Snow, V., Dimes, J.P., Silburn, M., Wang, E., Brown, S., Bristow, K.L., Asseng, S., Chapman, S., McCown, R.L., Freebairn, D.M., Smith, C.J. The Agricultural Production Systems Simulator (APSIM): its history and current capability. European Journal of Agronomy (in press).

Keen, P.G.W., 1975. Computer-based decision aids: the evaluation problem. Sloan Management Review $17-29$.

Keen, P.G.W., 1987. Decision support systems: the next decade. Decision Support Systems 3, $253-265$.

Keil, M., Beranek, P.M., Konsynski, B.R., 1995. Usefulness and ease of use: field study evidence regarding task considerations. Decision Support Systems 13, 75-91.

Little, J.D.C., 1970. Models and managers: the concept of a decision calculus. Management Science 16, B466-B485.

Malcolm, L.R., 1990. Fifty years of farm management in Australia: survey and review. Review of Marketing and Agricultural Economics 58, 24-55.

Martin, C.J., Clarke, B.A., 1990. Executive information systems: recent developments and research imperatives. British Journal of Management 1, 27-34.

McCown, R.L., 2001. Learning to bridge the gap between scientific decision support and the practice of farming: Evolution in paradigms of model-based research and intervention from design to dialogue. Australian Journal of Agricultural Research 52, 549-571.

McCown, R.L., 2002. Locating agricultural decision support systems in the troubled past and sociotechnical complexity of 'models for management'. Agricultural Systems, this issue.

McCown, R.L., Keating, B.A., Carberry, P.S., Hochman, Z., Hargreaves, D.M.G., 2002. The coevolution of the Agricultural Production Systems Simulator (APSIM) and its use in Australian dryland 
cropping research and farm management intervention. In: Ahuja, L.R., Ma, L., Howell, T.A. (Eds.), Agricultural System Models in Field Research and Technology Transfer. CRC Press, Boca Raton, FL.

Mingers, J., Gill, A., 1997. Multimethodology: The Theory and Practice of Combining Management Science Methodologies. John Wiley, West Sussex.

Mooney, P., 1988. My Own Boss?: Class, Rationality, and the Family Farm. Westview, Boulder, Colorado.

Moore, G.A., 1991. Crossing the Chasm: Marketing and Selling High-Tech Products to Mainstream Customers. Harper, New York.

Nardi, B.A., 1996. Context and Consciousness: Activity Theory and Human-Computer Interaction. MIT Press, Cambridge, MA.

Naylor, T.H., 1982. Decision support systems or whatever happened to M.I.S? Interfaces 12, 192-194.

Nelson, R.A., Holzworth, D.P., Hammer, G.L., Hayman, P.T. Infusing the use of seasonal climate forecasting into crop management practice in North East Australia using discussion support software. Agricultural Systems special issue on Seasonal Climate Forecasting, in press.

Oquist, P., 1978. The epistemology of action research. Acta Sociologica 21, 43-163.

Ormerod, R., 1995. Putting soft OR methods to work: information systems strategy development at Sainsbury's. Journal of the Operational Research Society 46, 277-293.

Parker, C., 1999. Decision support systems: lessons from past failures. Farm Management 10, 273-289.

Plant, R.E., 1997. Implementation of cotton crop management expert systems: lessons from 10 years of experience. AI Applications 11, 33-39.

Plant, R.E., 1989. An integrated expert decision support system for agricultural management. Agricultural Systems 29, 49-66.

Plant, R.E., Stone, N.S., 1991. Knowledge-Based Systems in Agriculture. McGraw Hill, New York.

Popper, K.R., 1972. Objective Knowledge: An Evolutionary Approach. Clarendon Press, Oxford.

Ravetz, J.R., 1971. Scientific Knowledge and its Social Problems. Oxford University Press, New York.

Reason, P., Bradbury, H., 2001. Handbook of Action Research: Participative Inquiry and Practice. Sage Publications, London.

Rogers, E.M., 1995. Diffusion of Innovations. Free Press, New York.

Roling, N., 1988. Extension Science: Information Systems in Agricultural Development. Cambridge University Press, Cambridge.

Room, P.M., 1979. A prototype 'on-line' system for management of cotton pests in the Namoi valley, New South Wales. Protection Ecology 1, 245-264.

Rosenhead, J., 1989. Introduction: Old and New Paradigms of Analysis. Rational Analysis for a Problematic World. John Wiley, Chichester.

Ryan, B., Gross, N.C., 1943. The diffusion of hybrid seed corn in two Iowa communities. Rural Sociology 8, 15-24.

Ryle, G., 1949. The Concept of Mind. Penguin, New York.

Schon, D.A., 1983. The Reflective Practioner: How Professionals Think in Action. Basic Books, USA.

Senge, P.M., 1990. The Fifth Discipline: The Art \& Practice of The Learning Organization. Doubleday, New York.

Simon, H.A., 1996. The Sciences of the Artificial, second ed. MIT Press, Cambridge, MA.

Stabell, C.B., 1987. Decision support systems: alternative perspectives and schools. Decision Support Systems 3, 243-251.

Stuth, J.W., Hamilton, W.T., Conner, R., 2002. Insights in development and deployment of the GLA and NUTBAL decision support systems for grazing lands. Agricultural Systems, this issue.

Suchman, L.A., 1987. Plans and Situated Action: The Problem of Human-Machine Interaction. Cambridge University Press, Cambridge.

Ulrich, W., 1991. Systems thinking, systems practice, and practical philosophy: a program of research. In: Flood, R.L., Jackson, M.C. (Eds.), Critical Systems Thinking: Directed Readings. John Wiley, Chichester, pp. 245-268.

Wagner, P., Kuhlmann, F., 1991. Concept and implementation of an integrated decision support system (IDSS) for capital-intensive farming. Agricultural Economics 3, 287-310. 
Watson, H.J., Hill, M.M., 1983. Decision support systems or what didn't happen with M.I.S. Interfaces $13,81-88$.

Welch, S.M., Jones, J.W., Brennan, M.W., Reeder, G., Jacobson, B.M., 2002. PCYield: Model-based decision support for soybean production. Agricultural Systems, this issue.

Winograd, T., Flores, F., 1986. Understanding Computers and Cognition: A New Foundation for Design. Ablex, Norwood.

Zadoks, J.C., 1989. EPIPRE, A computer-based decision support system for pest and disease control in wheat: Its development and implementation in Europe. In: Leonard, K.J., Fry, W.E. (Eds.), Plant Disease Epidemiology Vol 2: Genetics, Resistance, and Management. McGraw-Hill, New York. 